This PDF is a selection from a published volume from the National Bureau of Economic Research

Volume Title: Social Security Programs and Retirement Around the World: Disability Insurance Programs and Retirement

Volume Author/Editor: David A. Wise, editor

Volume Publisher: University of Chicago Press

Volume ISBNs: 0-226-26257-X, 978-0-226-26257-4 (cloth); 978-0-226-26260-4 (e-ISBN)

Volume URL: http://www.nber.org/books/wise14-1

Conference Date: September 26-28, 2013

Publication Date: January 2016

Chapter Title: Financial Incentives, Health, and Retirement in Spain

Chapter Author(s): Pilar García-Gómez, Sergi Jiménez-Martín, Judit Vall Castelló

Chapter URL: http://www.nber.org/chapters/c13332

Chapter pages in book: (p. $455-495)$ 


\title{
Financial Incentives, Health, and Retirement in Spain
}

\author{
Pilar García-Gómez, Sergi Jiménez-Martín, \\ and Judit Vall Castelló
}

\subsection{Introduction}

Developed countries share a considerable concern about the financial sustainability of their social insurance systems. The origin of these worries can be found in two well-documented phenomena: an unfavorable demographic process (see Diamond 2007; Lutz, Sanderson, and Scherbov 2008) and a tendency toward reducing the age of retirement on those economies (see Gruber and Wise 1999, 2004; Fenge and Pestieau 2005). Changes in demographics are characterized by increases in life expectancy and decreases

Pilar García-Gómez is an assistant professor at the Erasmus School of Economics of Erasmus University Rotterdam. Sergi Jiménez-Martín is associate professor of economics at Universitat Pompeu Fabra, Barcelona GSE, and director of LaCaixa-FEDEA Chair on Health Economics at FEDEA. Judit Vall Castelló is a researcher at the Centre for Research in Health and Economics (CRES), Department of Economics, Universitat Pompeu Fabra.

We thank the Ministerio de Ciencia e Innovación for financial support (research projects \#ECO2011-30323-C03-02 and ECO2014-52238-R). García-Gómez is a postdoctoral fellow of the Netherlands Organization for Scientific Research-Innovational Research Incentives Scheme-Veni. Vall Castelló thankfully acknowledges financial support from the Centre Cournot for Economic Research in Paris. This chapter uses data from SHARE wave 4, release 1.1.1, as of March 28, 2013, or SHARE waves 1 and 2, release 2.5.0, as of May 24, 2011, or SHARELIFE release 1, as of November 24, 2010. The SHARE data collection has been primarily funded by the European Commission through the 5th Framework Programme (project QLK6-CT2001-00360 in the thematic programme Quality of Life), through the 6th Framework Programme (projects SHARE-I3, RII-CT-2006-062193, COMPARE, CIT5-CT-2005-028857, and SHARELIFE, CIT4-CT-2006-028812) and through the 7th Framework Programme (SHARE-PREP, N²11909, SHARE-LEAP, N²27822, and SHARE M4, N²61982). Additional funding from the US National Institute on Aging(U01 AG09740-13S2, P01 AG005842, P01 AG08291, P30 AG12815, R21 AG025169, Y1-AG-4553-01, IAG BSR06-11, and OGHA 04-064) and the German Ministry of Education and Research as well as from various national sources is gratefully acknowledged (see www.share-project.org for a full list of funding institutions). For acknowledgments, sources of research support, and disclosure of the authors' material financial relationships, if any, please see http://www.nber.org/chapters/c13332.ack. 
in fertility rates, which is the worst-case scenario for the sustainability of pay-as-you-go systems. Furthermore, despite growing immigration, the oldage dependency ratio has not improved in the last few years, particularly in European countries. On the other hand, labor force participation by older individuals has been recently increasing, induced in many cases by appropriate regulatory changes introduced in many countries.

The Spanish case is not an exception in this panorama. First, fertility rates are among the lowest in Europe with values below 1.4 in the last years (Eurostat 2013) while, at the same time, the country has experienced large gains in life expectancy. The increase in life expectancy at birth has also been translated in increases in life expectancy at age sixty-five. In 1960 women age sixty-five expected to live 15.3 more years, while the expectations were 21.9 in 2008. Similar improvements are also observed among men (from 13.1 in 1960 to 18.0 in 2008) (García-Gómez, Jiménez-Martín, and Vall Castelló 2012). In parallel, the behavior of the Spanish labor market is puzzling. After a period of strong growth in participation and employment rates (especially for females) between 1995 and 2008 at all ages, the recent economic crisis has dramatically increased unemployment rates, which are currently around 27 percent of the working force (in 2013).

In this work we provide further evidence on the role that financial incentives and health play in transitions out of employment among older workers. The literature on the effect of financial incentives on retirement is very large (see, for example, Samwick [1998]; Coile and Gruber [2007]; Börsch-Supan [2000], for the European case). Within this literature some studies try to identify the interaction between health and financial incentives. For example, Kerkhofs, Lindeboom, and Theeuwes (1999) study the interplay between financial incentives and health in a dynamic programming model. They find that incentive effects are relatively insensitive to alternative specifications for health. Hagan, Jones, and Rice (2009) analyze comparable European Union (EU) data and find a strong relationship between health and early retirement. In the Spanish case, García-Gómez, Jiménez-Martín, and Vall Castelló (2012) analyze the trends in labor force participation and transitions to benefit programs of older workers in relation to health trends as well as recent social security reforms. They find little evidence that health improvements at the population level increase the labor market participation rates of older workers.

In this work we take advantage of the detailed health information available in the Survey of Health and Retirement in Europe to explore the link between health, financial incentives, and retirement. With this purpose, we construct a health index and classify individuals into health quintiles and use this information to assess the extent to which differences in health are translated into differences in the responsiveness to changes in financial incentives. In addition, we construct a single-option value measure by compiling the information on financial incentives from the disability, old-age, and unem- 
ployment systems in order to consider the aggregate incentives from all the social security schemes used as pathways into retirement among individuals ages fifty to sixty-four in Spain.

Our results show that individuals in the worse health quintiles are, indeed, more responsive to financial incentives as they prove to be less likely to retire when incentives to continue working increase. We further perform a series of simulations to assess the expected changes in retirement choices of older individuals when some of the policy parameters are modified.

The rest of the chapter is organized as follows. In section 11.2 we discuss the recent trends observed in the Spanish labor market and regulation. In section 11.3 we present the key ingredients of our empirical approach. We discuss the main result obtained from the analysis in section 11.4. Last, section 11.5 concludes.

\subsection{Background}

In this section we first provide some graphical evidence about trends in employment and participation in different social security programs (disability insurance [DI], unemployment insurance [UI], and old-age pensions [OAP]). Next, we review the generosity and entitlement characteristics of these programs and explain the main recent reforms.

\subsubsection{Trends in Employment and Participation in Different Social Security Programs}

In this section we provide some graphical evidence on social security participation by age groups, gender, and educational attainment. Data on employment, unemployment, and disability come from the Spanish Labor Force Survey (Encuesta de Población Activa [EPA]). The EPA is a rotating quarterly survey carried out by the Spanish National Statistical Institute (Instituto Nacional de Estadística [INE]). The planned sample size consists of about 64,000 households with approximately 150,000 adult individuals. Although the survey has been conducted since 1964, publicly released crosssectional files are available only from 1977. The 1977 questionnaire was modified in 1987 (when a set of retrospective questions were introduced), in the first quarter of 1992, in 1999, and 2004. The EPA provides fairly detailed information on labor force status, education, and family background variables but, like most of the other European-style labor force surveys, no information on health is provided. The reference period for most questions is the week before the interview.

Figure 11.1 shows the percentage of individuals in each social security program (unemployment, old-age benefits, and disability) for Spanish men in the age brackets fifty to fifty-four, fifty-five to fifty-nine, and sixty to sixtyfour. The percentage of individuals who report receiving disability benefits has remained stable, as shown in previous research (Vall Castelló 2012; 


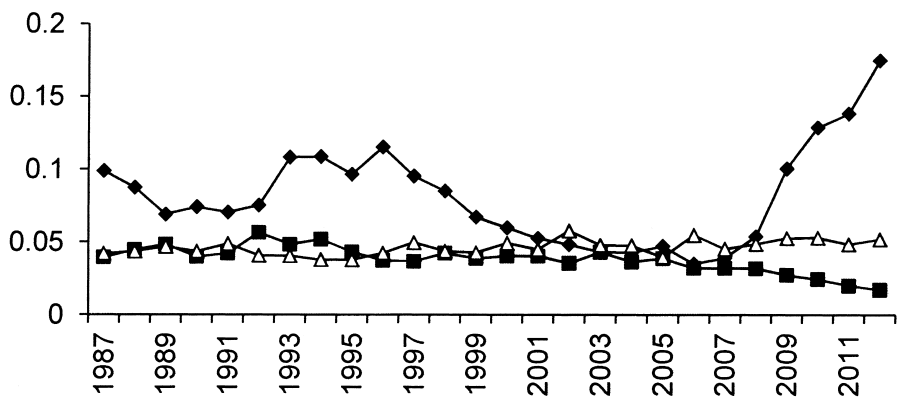

$\rightarrow$ Unemployment $\rightarrow$-Old age benefits $\rightarrow$ Disability insurance

Men 55-59

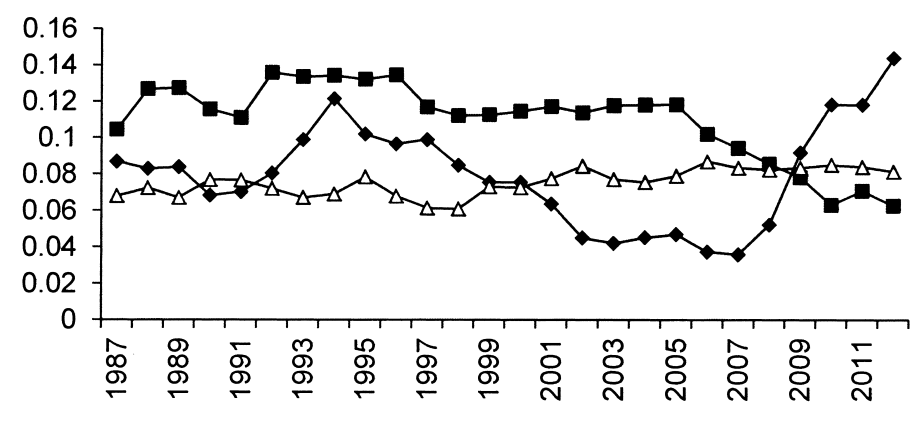

$\rightarrow-$ Unemployment $\rightarrow$-Old age benefits $\rightarrow-$ Disability insurance

Men 60-64

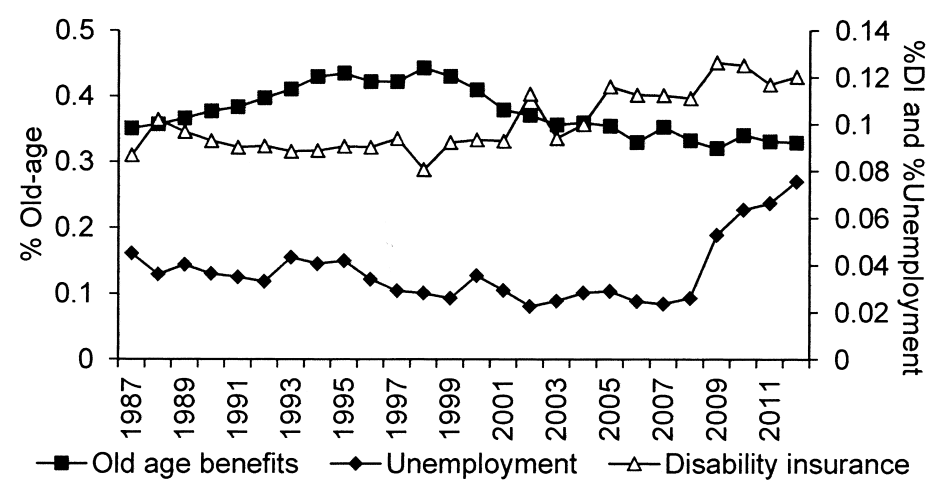

Fig. 11.1 Percentage of individuals in each social security program (self-reported). Men age fifty to sixty-four by age group

Source: Authors' own elaboration using data from the Spanish Labor Force Survey. 
García-Gómez, Jiménez-Martín, and Vall Castelló 2012). While the inflow into DI has been growing steadily in a number of countries, this rate has remained quite stable in Spain (see Wise 2012). However, the percentage of individuals in disability has begun to increase at the end of the period for the elderly group of workers (as seen in figure 11.1). This could be the result of a worsening in labor market conditions as indicated by the increase in unemployment rates at the same time that early retirement becomes less attractive as the decreasing trends suggest.

The percentage of individuals in the old-age benefit system was increasing for both age groups until 1996, but since that date it has experienced a decreasing trend. Reforms introduced in 1997 and 2002 (especially the second one that delayed early retirement until age sixty-one) in the old-age benefit system (explained in detail in the next section) are partly responsible for this decreasing trend (see Jiménez-Martín 2006). The high fraction in old-age benefits in the fifty-five to fifty-nine age group showed by the Spanish Labor Force Survey is likely to be due to participation in preretirement schemes that do not involve automatic retirement (Dorn and Souza-Poza 2010; Boldrin, Jiménez-Martín, and Peracchi 1999). Alternatively, individuals may declare themselves as retired because they have exited permanently from the labor force even though they could be receiving benefits from another scheme. Therefore, in practice, individuals perceive this situation as a retirement path.

Last, we can see that the unemployment rates of the youngest group of workers are more sensitive to the business cycle compared to individuals entitled to early retirement benefits (see next section), although the severity of the current economic crisis in Spain has translated into increases in the unemployment rate for men in all age groups.

Figure 11.2 plots the share of men and women that report receiving DI benefits by age group (fifty to fifty-four, fifty-five to fifty-nine, and sixty to sixty-four). We can observe that contrary to the relatively stable trend observed for males (see figure 11.1), participation in the DI program has experienced a sizable increase among women in the three age groups. The increase in female DI participation rates in Spain begins in the mid-1990s and it slows down during the current period of economic crisis. This is an expected increase given the increase in female participation rates observed in the past that allow a larger share of women to be entitled to DI. In any case, for both men and women the strong economic crisis experienced by the Spanish economy does not seem to have increased or decreased the percentage of individuals in DI for any of the three age groups.

Figure 11.3 shows the evolution of the percentage of males and females in the labor force and receiving DI benefits. The increase in DI participation rates for both men and women in the age group sixty to sixty-four reported in figures 11.1 and 11.2 is linked to the increase in the labor force participation rates for both groups from the mid-1990s. For the case of men, however, 

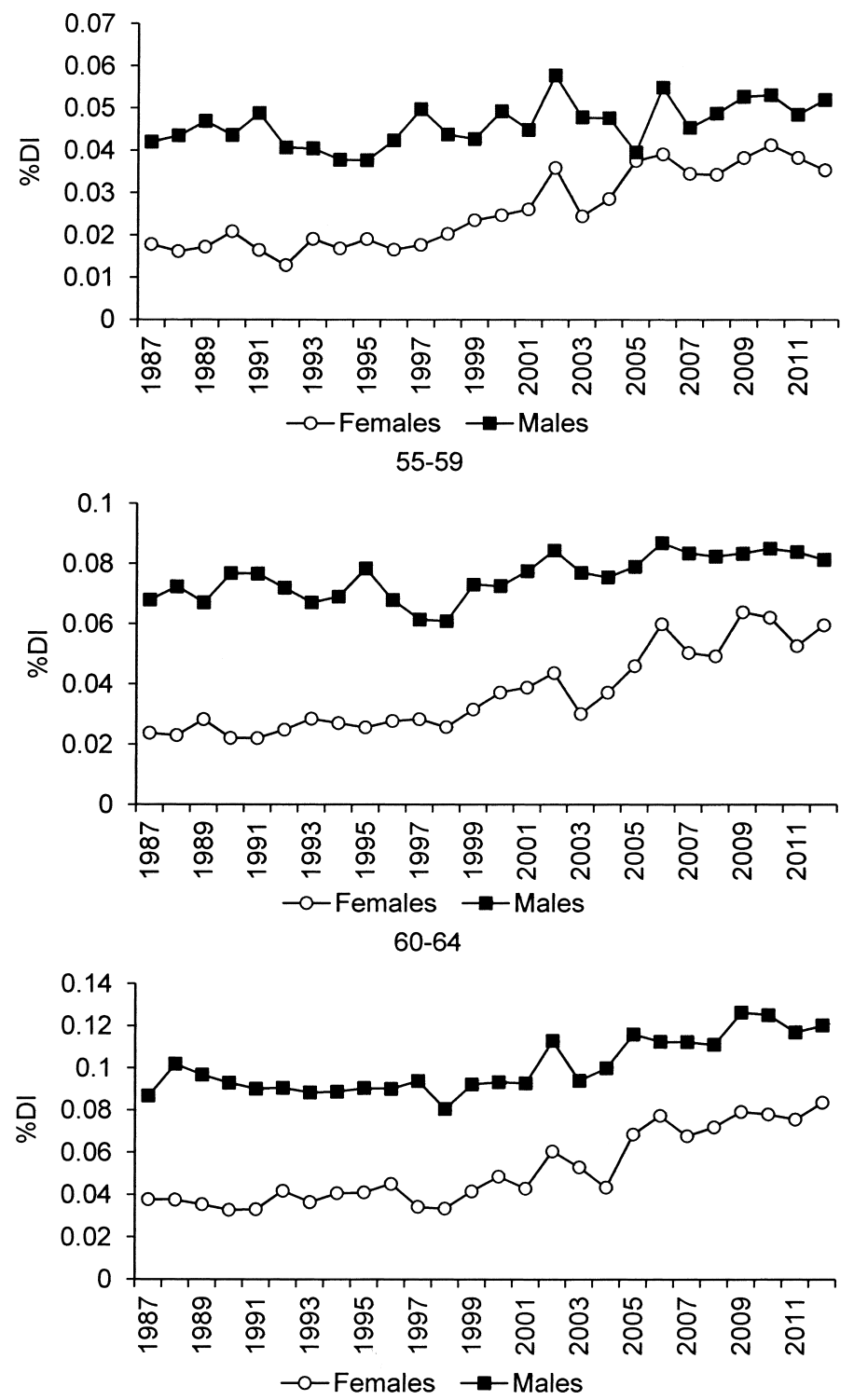

Fig. 11.2 The DI participation rates at ages fifty to fifty-four, fifty-five to fiftynine, and sixty to sixty-four by gender

Source: Authors' own elaboration using data from the Spanish Labor Force Survey. 


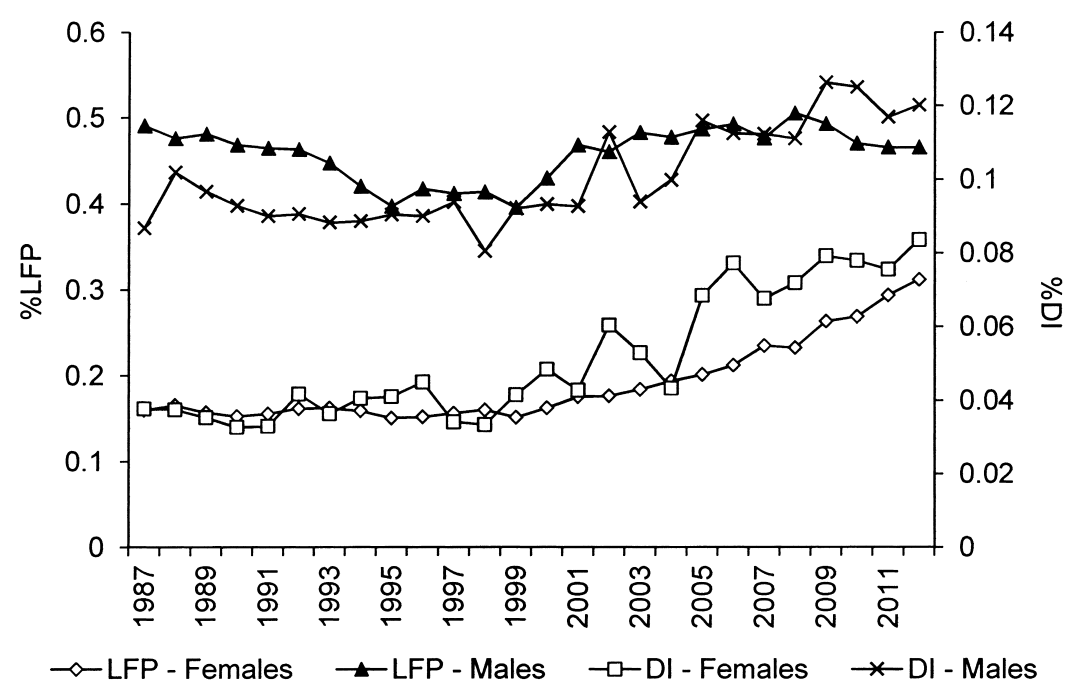

Fig. 11.3 Labor force and DI participation rates at ages sixty to sixty-four by gender

Source: Authors' own elaboration using data from the Spanish Labor Force Survey.

there is a change in this increasing trend from 2008 in which the participation in the labor force experienced a mild drop due to the economic crisis. This drop seems to have also been translated into a drop in DI participation rates for men, although with a two-year lag. Notice that labor force and DI participation rates are still increasing among women despite the economic crisis.

Figure 11.4 plots the evolution of DI participation rates by educational attaintment. The figure shows the share of men and women age fifty-five to sixty-four who report being on disability insurance among those who have completed either primary education, secondary education, or hold a university degree. There is an educational gradient in these percentages for both males and females, but the differences are more striking among males. The percentage into DI is largest among individuals with primary education at most, and lowest among those with a university degree. Figure 11.4 also shows that the recent increase in the share of the population in DI among women age fifty-five to sixty-four is mainly driven by the increase in the percentage of low-educated women in the disability insurance system. It is difficult to disentangle whether this increase is due to business cycle conditions or to a number of reforms that were introduced in the retirement and DI system in 1997 (see next section).

Last, figure 11.5 shows the trends in employment for men and women age sixty to sixty-four in Spain by educational attainment. For both men and women we can see that the highest employment rates are for individuals 


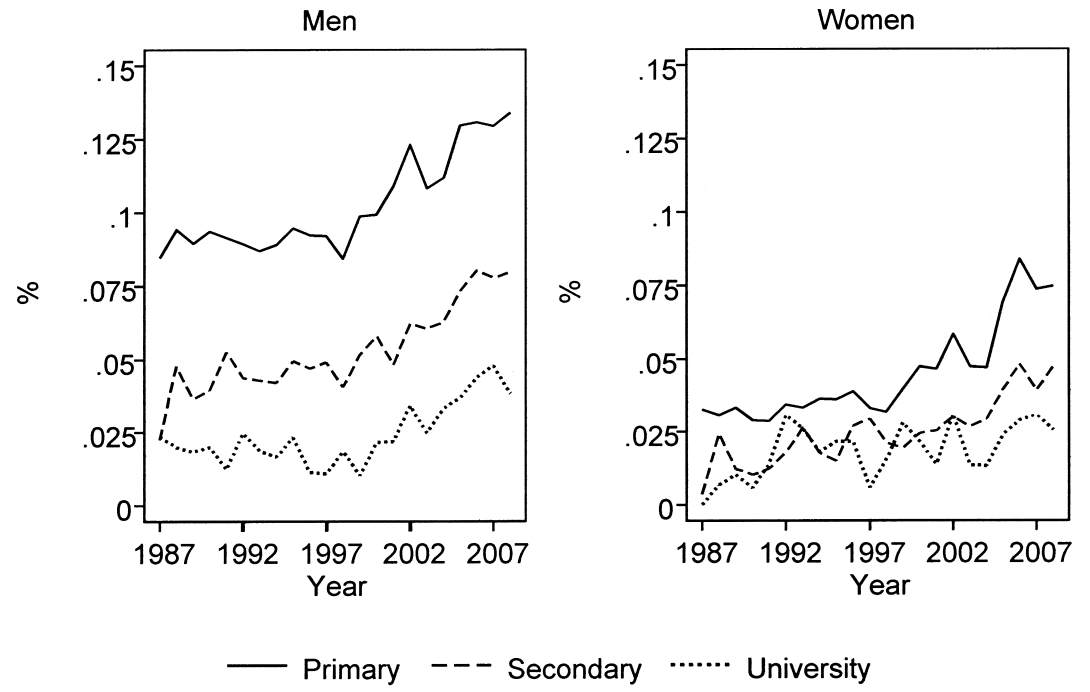

Fig. 11.4 Share of the population age fifty-five to sixty-four into disability insurance (self-reported) by educational attainment

Source: Authors' own elaboration using data from the Spanish Labor Force Survey.

with a university degree, which are also the ones with a lower percentage of individuals on the disability rolls. This difference in employment rates by education is more pronounced for the case of women. In general terms, we can see that employment has been decreasing from 1987 until 2008 for men with a university degree, while it has remained relatively stable for men with primary or secondary education (although both groups experience a drop in employment in times of economic slowdowns such as the first half of the 1990s, as well as in the recent economic crisis). On the contrary, female employment rates for the two lowest educational groups seem to be mildly increasing since the 1980s, and they seem to be less responsive to the business cycle conditions than the male employment rate.

\subsubsection{Institutional Background}

\section{Disability Insurance}

In Spain, there are two types of permanent disability benefits: (a) contributory, which are given to individuals who have generally contributed to the social security system before the onset of the disabling condition; and (b) noncontributory, which are given to individuals who are assessed to be disabled but have never contributed to the social security system (or do not reach the minimum contributory requirement to access the contributory 
Men 60-64

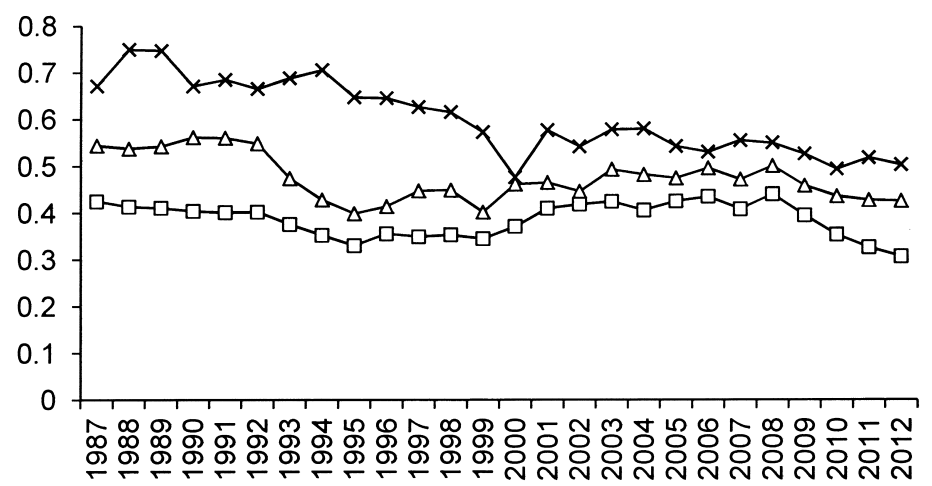

$\rightarrow-$-Primary $\rightarrow$-High-school $\rightarrow$ College

Women 60-64

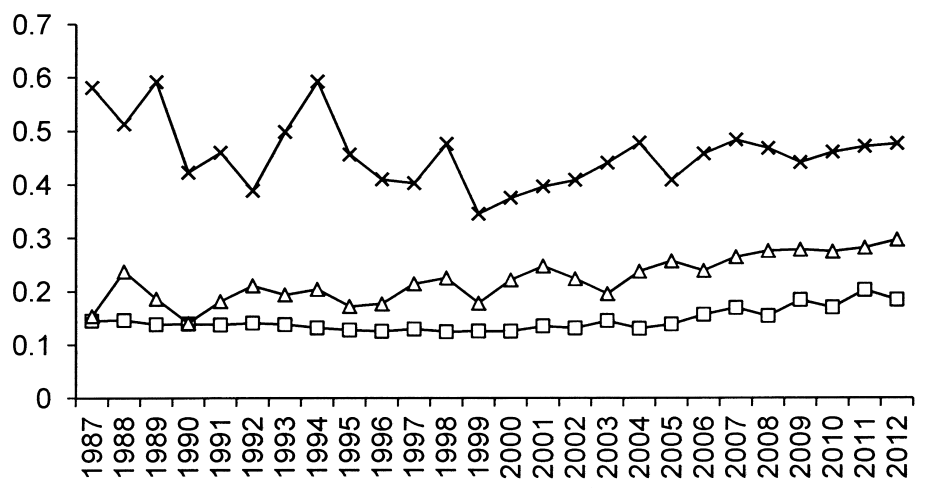

$$
\rightarrow-\text { Primary } \triangle \text {-High-school } \quad * \text { College }
$$

Fig. 11.5 Employment rates for men and women at ages sixty to sixty-four by education

Source: Authors' own elaboration using data from the Spanish Labor Force Survey.

system). Noncontributory disability benefits are means tested and managed at the regional level. ${ }^{1}$

The size of the noncontributory system is relatively small compared to the contributory system $(195,986$ individuals received noncontributory disability benefits in October 2013, while 932,245 received contributory benefits during the same year). The amount of benefits received is also smaller in the

1. Income is evaluated yearly. The income threshold in 2010 was set at 4,755.80 euros per year for an individual living alone. This amount is adjusted if the individual lives with other members. 
noncontributory case (the average noncontributory pension is 396.92 euros per month compared to an average contributory disability pension of 909.25 euros per month). For these reasons, in the remaining of this chapter we put more emphasis on the permanent contributory disability system in Spain.

Social security defines the permanent contributive disability insurance as the economic benefits to compensate the individual for losing a certain amount of wage or professional earnings when affected by a permanent reduction or complete loss of his/her working ability due to the effects of a pathologic or a traumatic process derived from an illness or an accident.

The Spanish Social Security Administration uses a classification of four main degrees of disability that depend on the working capacity lost: ${ }^{2}$

1. Permanent limited disability for the usual job. The individual loses at least 33 percent of the standard performance for his/her usual job, but the individual is still able to develop the fundamental tasks of his/her usual job or professional activity. Individuals in this level of disability only receive a one-time, lump-sum payment.

2. Partial disability. The individual is impaired to develop all or the fundamental tasks of his/her usual job or professional activity, but he/she is still capable of developing a different job or professional activity.

3. Total disability. The individual is impaired for the development of any kind of job or professional activity.

4. Severe disability. Individuals who, as a result of anatomic or functional loses, need the assistance of a third person to develop essential activities of daily living such as eating, moving, and so forth.

The eligibility requirements and the pension amount depend on the source of the disability (ordinary illness, work related, or unrelated accident or occupational illness), the level of the disability, and the age of the onset of the disability. Table 11.1 summarizes the main parameters of both the eligibility criteria and the pension formula. The two main features to highlight are that: (a) there are not contributory requirements if the health impairment is due to either an accident or an occupational illness, and (b) individuals older than fifty-five with a partial disability receive a higher replacement rate if it is considered difficult for them to find a job due to lack of education or the social and labor market conditions of the region where they live.

The total amount of the pension is obtained by multiplying a percentage, which varies depending on the type of pension and the degree of disability (as shown in the last rows of table 11.1) to the regulatory base, which depends on the source of the disability and on previous salaries. ${ }^{3}$ The num-

2. Partial disability claimants represent 57 percent, total disability claimants represent 40 percent, and severe disability claimants represent 3 percent of all individuals in the DI system. The remaining 0.4 percent are individuals in the permanent limited disability system, which is being extinguished. These numbers are taken from the Muestra Continua de Vidas Laborales.

3. Benefit $=$ Regulatory Base $*$ Percentage. 
Table 11.1

Summary of the parameters to calculate permanent disability pensions

\begin{tabular}{|c|c|c|c|}
\hline & Ordinary illness & $\begin{array}{l}\text { Work-unrelated } \\
\text { accident }\end{array}$ & $\begin{array}{l}\text { Work-related accident } \\
\text { or professional illness }\end{array}$ \\
\hline Eligibility & $\begin{array}{l}\text { Age }>=31 \text { : } \\
\text { Contributed } 1 / 4 \text { time } \\
\text { between } 20 \text { years old } \\
\text { and disabling condition. } \\
\text { Minimum of } 5 \text { years } \\
\text { Age }<30 \text { : } \\
\text { Contributed } 1 / 3 \text { time } \\
\text { between } 16 \text { years old } \\
\text { and disabling condition. } \\
\text { No minimum number } \\
\text { of years required }\end{array}$ & $\begin{array}{l}\text { No minimum } \\
\text { contributory period } \\
\text { required }\end{array}$ & $\begin{array}{l}\text { No minimum } \\
\text { contributory period } \\
\text { required }\end{array}$ \\
\hline $\begin{array}{l}\text { Regulatory } \\
\text { base }\end{array}$ & $\begin{array}{l}\text { Average wage last } 8 \\
\text { years of } \\
\text { work* }^{*} \text { percentage }\end{array}$ & $\begin{array}{l}\text { Average annual wage } \\
\text { of } 24 \text { months within } \\
\text { the last } 7 \text { years of } \\
\text { work }\end{array}$ & $\begin{array}{l}\text { Average wage last } \\
\text { year of work }\end{array}$ \\
\hline $\begin{array}{l}\text { Percentage } \\
\text { applied to the } \\
\text { regulatory base }\end{array}$ & \multicolumn{3}{|c|}{$\begin{array}{l}\text { Partial disability: } 55 \% \\
\text { Individuals older than } 55 \text { with difficulties to find a job due to lack of } \\
\text { education or characteristics of the social and labor market of the region } \\
\text { where they live: } 75 \%\end{array}$} \\
\hline
\end{tabular}

${ }^{a}$ This percentage depends on the number of years contributed to the system at the age at which the individual enters the DI system. This percentage can range from 50 percent to 100 percent. This change was introduced in 2008 in order to make the formula to calculate the DI benefits closer to the formula used to calculate the old-age benefits.

ber of years included in the regulatory base depends on the source of the disability.

The income tax rules differ across disability types. Partial disability benefits are taxable under the general income tax rules, while total disability pensions are always exempted from income taxes. Furthermore, if the individual works while receiving the pension, there is a reduction in the earnings used to calculate the income tax of 2,800 euros per year if their degree of disability is low (between 33 percent and 65 percent) and of 6,200 euros per year if the disability level is higher (more than 65 percent) or if the disabled has reduced mobility. In addition, individuals receiving partial disability benefits can combine the benefits with earnings from work, as long as the type of job is compatible with his/her disability.

In general, to be granted a permanent disability benefit, the individual must come from a situation of sick leave (also called temporary disability/incapacity) and be observed as still presenting anatomic or functional 
reductions that decrease or cancel his/her capacity to work after following the prescribed medical treatment. The application can be started by the provincial office of the National Institute of Social Security (NISS), by the institutions that collaborate in the process (such as hospitals), or by the individual himself (in which case, more documentation is required). The Disabilities Evaluation Team evaluates the medical report and the professional background of the applicant and, on the basis of this analysis, the directors of the provincial office of the NISS decide on the type of disability pension granted (if any), the benefit level, and the date of the next medical check-up. All permanent disability pensions are automatically converted to old-age pensions once the individual turns sixty-five. ${ }^{4}$

\section{Old-Age Pensions}

Eligibility to the old-age pension benefits in Spain requires having contributed to the system for at least fifteen years and an individual can enter the system at the normal retirement age of sixty-five if the individual does not have any job that requires affiliation to the social security system. ${ }^{5}$ The pension amount is calculated by multiplying a regulatory base ${ }^{6}$ by a percentage that depends on the age of the individual and the number of years contributed to the system. If the individual enters the old-age system after the normal retirement age of sixty-five, there is an additional percentage that will also be multiplied to the regulatory base.

The regulatory base is obtained by dividing by 210 the wages of the last 180 months before retiring, and the percentage applied to this regulatory base is the following: ${ }^{7}$

$$
\begin{cases}0 & \text { if } n<15 \\ 0.5+0.03(n-15) & \text { if } 15 \leq n \leq 25 \\ 0.8+0.02(n-25) & \text { if } 25<n<35 \\ 1 & \text { if } 35 \leq n\end{cases}
$$

4. Most of the outflows from the permanent disability system are due to death or automatic transfer to old-age pensions. Around 4 percent of the outflows are due to improvement of the health condition and 2.7 percent to a judicial process. Monthly outflows in 2010 were around $2,500-3,000$.

5. This condition was later relaxed in 2002 when partial retirement was introduced.

6 . The benefit base is a weighted average of monthly earnings over the last eight years of work before retirement. This was changed to fifteen years of work before retirement from 1997. However, this change was introduced gradually from 1997 until 2002 and it affected all individuals in the same way. Therefore, we have reason to think that this change will not interfere in our results. See Boldrin and Jiménez-Martín (2007) for further details of the Spanish system and the reforms undertaken.

7. Both the calculation of the regulatory base and the percentage applied to this regulatory base was changed by a reform in 2011. However, we do not explain this reform in the current chapter as it is outside the years included in our sample period. 


\section{Unemployment Insurance}

According to the current unemployment rules, there are two kinds of unemployment benefits. Unemployment insurance (UI) is available for eligible ${ }^{8}$ workers that contributed while employed and have been fired from the previous job. After the exhaustion of UI benefits, unemployment assistance (UA) is available for individuals who have finished their UI contributory period. Individuals entering the UI scheme are entitled to receive 70 percent of the wages of the last 180 days of work during the first six months and 60 percent after that. ${ }^{9}$ These quantities are subject to a minimum and a maximum amount. The minimum corresponds to 80 percent of the minimum wage and the maximum corresponds to 175 percent of the minimum wage. Both quantities are increased if the individual has, at least, one dependent child. ${ }^{10}$ These benefits are paid for a period of one-third of the accumulated job tenure and are only paid for a maximum period of two years.

The UA benefits are only paid to individuals with an average family income below 75 percent of the minimum wage. There is a fixed amount paid that corresponds to 80 percent of the minimum wage. This benefit is only paid for a maximum period of twenty-one months if the individual has contributed for at least six months and if he/she has dependents. ${ }^{11}$ There are, however, two special continuation programs for those who have exhausted their entitlement to contributory unemployment benefits: one for those age forty-five and older (UB45+ program), and the other for those age fifty-two and older (UB52+ program). The latter is a special subsidy for unemployed people that are older than fifty-two, have a family income lower than 75 percent of the minimum wage, have contributed to unemployment insurance for at least six years in their lifetimes and, except for age, satisfy all the requirements for an old-age pension. ${ }^{12}$ Those in the UB52+ program keep contributing toward the pension, but at the minimum contributory base and they can receive 80 percent of the minimum wage until they reach the official retirement age. (García-Pérez, Jiménez-Martín, and Sánchez-Martín 2013; Jiménez-Martín and Vall Castelló 2013).

8. They must have accumulated 360 days of contributions to the Social Security Administration during the previous six years before becoming unemployed.

9. A reform introduced in 2012 decreased this amount to 50 percent (instead of 60 percent) of last earnings after the first six months receiving UI benefits.

10. For individuals with at least one dependent child, the minimum amount corresponds to 107 percent of the minimum wage and the maximum amount corresponds to 200 percent of the minimum wage.

11. If the person has contributed for at least six months but does not have dependents, the duration of the subsidy is six months. If the person does not have dependents and has not contributed for at least six months, he/she cannot receive the subsidy. There is also a special scheme in Andalucía and Extremadura for agricultural workers who have been employed for forty days during the year. They are entitled to receive 75 percent of the minimum wage for 90 to 300 days each year. The number of days depends on their age and number of dependents.

12. The age of fifty-two was changed to fifty-five in July 2012. 


\section{Main Reforms}

Permanent disability benefits were used extensively as an early retirement mechanism for workers in restructuring industries (such as shipbuilding, steel, mining, etc.) or as a substitution for long-term unemployment subsidies in depressed regions during the late 1970s and 1980s (OECD 2001), which resulted in an increase in the inflows into the disability system and permanent disability benefits.

These events prompted a number of reforms introduced during the second half of the 1980s and beginning of the 1990s that aimed at reversing these trends (see table 11.2 for a summary). The main objective of these reforms was to abolish the incentive effects to permanently leave the labor market before reaching the legal retirement age through the disability system.

Here we focus on some distinctive features of the main reforms since the creation of the National Institute of Social Security in 1979, while we refer the reader to table 11.2 for a summary of all the reforms in the disability system in Spain during this period.

The first major reform of the disability system took place in 1997 and it included four main points:

1. Sickness benefits. Stricter control of the sickness status by doctors of the social security system, reduction of the level of long-term sickness benefits, and replacement of the old own-job assessment by a more objective definition of the usual occupation of the individual.

2. Permanent disability pensions of individuals at least sixty-five years of age are automatically transferred to the old-age pension system. This is just a change in the classification within the pensions system.

3. Organizational reform. All the permanent disability matters are transferred to the NISS. In the past, the permanent disability status was assessed and granted by local general practitioners and this reform created a group of experts (the disability assessment team inside the NISS) that would be in charge of assessing a person's ability to work on the basis of the available medical files and a special medical assessment done by one of the NISS doctors.

4. The individual does not lose entitlement to noncontributory disability benefits if he/she starts working. He/she will then still be entitled to receive noncontributory disability benefits if he/she loses his/her job.

Apart from this major reform in 1997, the 1998 budget law introduced the possibility for doctors from the NISS and mutual insurance companies to review the health situation and status of beneficiaries. However, in reality, very few individuals in the permanent disability system do effectively lose their benefits. In 2004 and 2005, monitoring of the use of sickness leave was tightened with the creation of a new subdepartment at the NISS and a new monitoring tool to reduce absence rates. In 2005, a general absence control 
1984 Introduction of temporary contracts.

Introduction of unemployment assistance (UA) benefits (noncontributory).

Special provision for workers age 55+; they can receive UA until retirement if comply with requirements to get old-age pension (except age requirement).

1985 The terms of eligibility for disability pensions are tightened.

Increased the minimum mandatory annual contributions from 8 to 15 .

The number of contributive years used to compute the pension increases from 2 to 8 .

Several early retirement schemes are introduced; partial retirement and special retirement at age 64 .

1989 Special scheme of UA (permanent until retirement) extended to workers 52+.

1990 Introduction of a means-tested noncontributory disability pensions for peopled age 65+ and for disabled people age $18+$ who satisfy residency requirements.

1997 Stricter control of sickness status, reduction of long-term sickness benefit level, usual occupation replaces own job assessment.

Permanent disability pensions to individuals $65+$ are converted to old-age pensions.

New INSS disability assessment team to assess permanent disability instead of the GP.

Entitlement to noncontributory benefits is not lost if working, and can be collected if losing the job.

The number of contributive years used to compute the pension increases from 8 to 15 (progressively by 2001).

The formula for the replacement rate is made less generous.

The $8 \%$ penalty applied to early retirees between the ages of 60 and 65 is reduced to $7 \%$ for individuals with 40 or more contributory years.

Introduction of a new permanent contract with reduced severance payments targeted to certain population groups.

Lower social security contributions for employers for the first two years if one of these new permanent contracts was signed.

1998 Possibility of doctors from INSS and mutual insurance companies to review the health situation of beneficiaries.

2001 Broaden the 1997 labor market reform.

Extension of new permanent contract of 1997 to more population groups.

Suppression or reduction of social security contributions to support permanent employment for certain groups of the population.

$2002 \quad$ Early retirement only from age 61.

Impulse partial retirement; possible to combine it with work.

Unemployed at age 61 can retire if contributed for 30 years and the previous 6 months registered in employment offices.

Incentives to retire after age 65 .

Individuals age 52+ can combine unemployment benefits with a job.

Extension of group of individuals that can benefit from the "integration contract" (program to help integrate the unemployed into the labor market).

2004-2005 Improve monitoring and control of sickness leave with new INSS tool.

Possibility to combine noncontributory disability with some earnings. 
Table 11.2 (continued)

2007 Minimum contributory period to access permanent disability is reduced for young workers.

The formula to calculate the regulatory base of the DI benefit gets closer to the formula for old-age pensions.

Fifteen "effective" contributory years are used to calculate the old-age pension.

Reduction from $8 \%$ to $7.5 \%$ of the per-year penalty applied to early retirees between 60 and 65 for individuals with 30 contributory years.

Broaden incentives to stay employed after age 65 .

Increase contributions made by the Social Security Administration for individuals receiving the special scheme of UA for 52+ (they will receive a higher old-age pension when retiring).

2011 Gradual increase (from 2013 until 2027) of the normal retirement age from 65 to 67 depending on the age of the individual as well as on the number of years and months of contributions accumulated during his/her labor market career. to $50 \%$ of previous earnings.

was put in place for cases in which the absenteeism took longer than six months.

Finally, at the end of 2007, the minimum contributory period to access permanent disability pensions was reduced for young workers in order to adjust for the current later entrance into the job market of younger workers. At the same time, the formula to calculate the regulatory base of the benefit was slightly modified: the regulatory base of permanent disability due to a common illness is since then decreased by 50 percent if the individual had not contributed at least fifteen years, and it is lower the further the individual is from age sixty-five.

All these reforms have ensured the financial stability of the disability system in Spain as inflow rates have remained at stable levels and have not experienced any dramatic increases like in other countries.

The extent to which reforms in the disability system are able to decrease the outflows from employment at older ages will depend on the evolution of other programs that can be used as alternative early retirement routes. Therefore, in this section we summarize other important reforms that have taken place in other social security programs in Spain. In particular, we focus on reforms in the unemployment and old-age systems. Table 11.3 provides a chronological summary of these reforms. ${ }^{13}$

In 1984, both temporary contracts and noncontributory unemployment benefits (also called unemployment assistance benefits) were introduced.

13. A detailed exposition of the changes in the old-age pension system in Spain is provided in Boldrin, García-Gómez, and Jiménez-Martín (2010). 
The PVW first principal component index for Spain

\begin{tabular}{lc}
\hline Variable & Factor loading \\
\hline Difficulty walking 100 meters & 0.2737 \\
Difficulties lifting or carrying weights over 100 pounds/5 kilos & 0.3011 \\
Difficulties pulling or pushing large objects & 0.2938 \\
Difficulty with an ADL (0 if no limitations; 1 if 1 or more limitations) & 0.2826 \\
Difficulty climbing stairs & 0.3066 \\
Difficulties stooping, kneeling, or crouching & 0.3045 \\
Difficulties getting up from a chair & 0.2919 \\
Self-reported health fair or poor & 0.2594 \\
Difficulties reaching or extending your arms above your shoulder & 0.2514 \\
Doctor has ever told you have arthritis, including osteoarthritis, or & \\
$\quad$ rheumatism & 0.2007 \\
Difficulties sitting two hours & 0.2255 \\
Difficulties picking up a small coin from a table & 0.1828 \\
Pain in back, knees, hips, or any other joint at least during the past six & \\
$\quad$ months & 0.1952 \\
Heart trouble or angina or chest pain during exercise at least for the past & \\
$\quad$ six months & 0.1345 \\
Hospital stay & 0.1202 \\
Home care & 0.0884 \\
Doctor visit & 0.07 \\
Ever experience psychological problems & 0.0938 \\
Doctor has ever told you have a stroke or cerebral vascular disease & 0.0925 \\
Doctor has ever told you have high blood pressure or hypertension & 0.119 \\
Doctor has ever told you have a chronic lung disease such as chronic & \\
$\quad$ bronchitis or emphysema & \\
Doctor has ever told you have diabetes or high blood pressure & 0.0899 \\
BMI & 0.0947 \\
Nursing home stay & 0.0844 \\
Doctor has ever told you have cancer or malignant tumor, including & 0.0305 \\
leukemia or lymphoma, but excluding minor skin cancers & \\
Observations & 0.036 \\
Percent total variance explained & 7,480 \\
\hline
\end{tabular}

Note: Values based on SHARE data for 2004, 2006, and 2010.

In addition, a special provision was established for workers over fifty-five years of age who were allowed to receive unemployment assistance benefits until retirement age. To receive these benefits, individuals had to satisfy the entitlement requirements of the retirement pension, except for the age. The subsidy paid 75 percent of the minimum wage until reaching the age to be transferred to an old-age pension. Furthermore, the years spent unemployed under this special scheme were counted as contributive years toward an old-age pension.

In the following year, 1985, an old-age pension reform was passed that increased the minimum mandatory annual contribution to old-age pensions 
from eight to fifteen years, it also increased the number of years of contribution used to calculate the pension from two to eight years ${ }^{14}$ and introduced several early retirement programs linked to hiring a new worker, such as the partial retirement program that allowed part-time retirement at sixty-three by combining part-time wages and old-age pension, and special retirement at sixty-four if the employer hired a registered unemployed.

In 1989 the special provision of unemployment assistance benefits until the retirement age of sixty-five for individuals at least fifty-five years of age was extended to individuals at age fifty-two, thus increasing the incentives of older workers to leave the labor market at younger ages. The expected decrease in the labor force participation rates of older individuals observed in Spain during the 1980s and the early 1990s prompted the government to adopt a change in the strategy, and to start a series of reforms to reverse these negative labor market trends. Therefore, the reforms introduced during the 1990s had the objective of keeping older workers active in the labor market for longer.

There have been two main reforms since the mid-1990s, one in 1997 and the other in 2002. In 1997 the number of contributory years used to compute the benefit base was progressively increased from eight to fifteen years and the formula to calculate the replacement rate was also made less generous. ${ }^{15}$ On the other hand, the 8 percent penalty applied to early retirees between the ages of sixty and sixty-five was reduced to 7 percent for individuals with forty or more years of contributions at the time of early retirement. Some changes in the incentives on the demand side were also introduced in 1997 to reduce the unemployment rates and the share of temporary contracts among the disadvantaged groups, including individuals age forty-five or older who were either unemployed or had a temporary contract.

In 2002 changes in both the old-age and the unemployment systems were introduced. Before 2002, only individuals who had contributed to the system earlier than 1967 could benefit from early retirement at sixty, while the rest had to wait until the normal retirement age of sixty-five. In 2002, earlier retirement at age sixty-one was made available for the rest of the population. At the same time, there was an impulse to the partial and flexible retirement schemes with the possibility of combining income from work with old-age benefits and the introduction of incentives for individuals to retire after the legal retirement age of sixty-five (an additional 2 percent per additional year of contribution beyond the age of sixty-five for workers with at least thirty-

14. The change in the minimum mandatory annual contributions to have access to an oldage pension affected all individuals since 1985, but the number of years used to calculate the pension was progressively increased: during the first year, the last seventy months were used, seventy-two months in the second year, and eighty-four in the third year.

15. In 1997 the last 108 months are included, the last 120 months in 1998, the last 132 months in 1999 , the last 144 months in 2000 , the last 156 months in 2001 , and the last 180 months from 2002 onward. 
five years of contributions on top of the 100 percent applied to the regulatory base). At the same time, the possibility to access retirement was extended to individuals who are unemployed for reasons beyond their willingness at age sixty-one and who have contributed for at least thirty years and have been registered in the employment office for the previous six months.

On the other hand, the reform in 2002 opened up the possibility for individuals age fifty-two or older who are receiving unemployment benefits to combine the receipt of these benefits with earnings, as they could receive 50 percent of normal benefits and the employer would pay the remaining quantity in wages. In addition, it extended the program that helps to integrate unemployed persons in the labor market to all individuals at least forty-five years of age who have been unemployed for one month and to people with disabilities, among others. ${ }^{16}$

In 2007 the incentives to retire later than age sixty-five were further increased providing an additional 3 percent, instead of the 2 percent agreed on in 2002. Moreover, in order to have access to an old-age pension the individual must have contributed for at least two out of the last fifteen years and the proportional part related to the extra monthly salaries will not be taken into account when computing the number of contributed years. On the other hand, the 8 percent penalty applied to early retirees between the ages of sixty and sixty-five was reduced to 6-7.5 percent, depending on the number of years contributed, for those individuals with thirty years of contributions. In addition, the contributions for unemployed workers older than fifty-two were increased so that they would receive a higher old-age pension when retiring.

Last, in 2011 a new reform was introduced that gradually moved (from 2013 until 2027) the normal retirement age from sixty-five to sixty-seven, depending on the age of the individual as well as the number of years and months of contributions accumulated during his/her labor market career. However, as this last reform was introduced after the end of our sample period, we do not enter into the details of the policy change. Similarly, the amount an individual receives from UI after the first six months was reduced from 60 to 50 percent of previous earnings in 2012.

\subsection{Empirical Approach}

\subsubsection{Pathways to Retirement}

We use retrospective information available in the second quarter of the EPA regarding the labor status of individuals in the previous year to investigate which are the pathways used to leave the labor market in Spain. We calculate the percentage that transit from employment to each of the statuses

16. This program is called Contrato de Integración (Integration Contract). 
Men 55-59

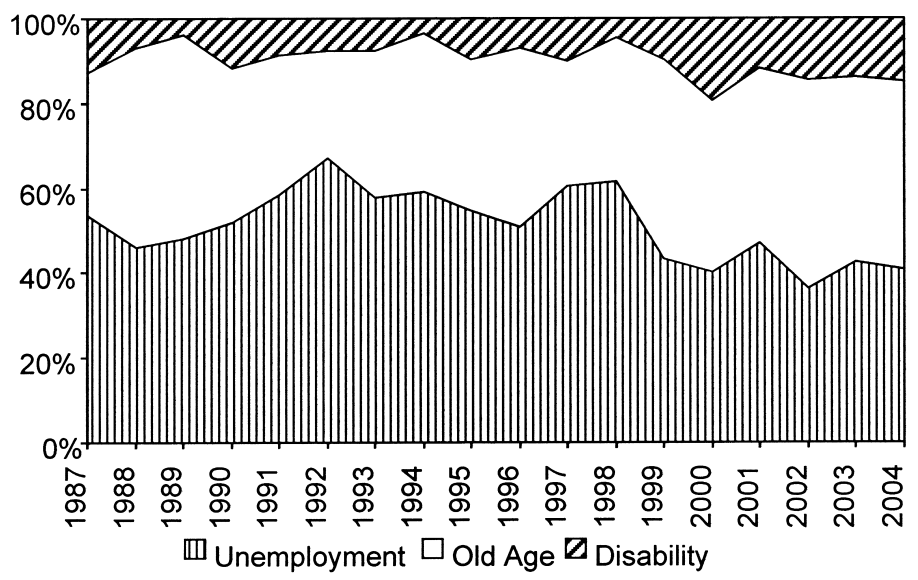

Men 60-64

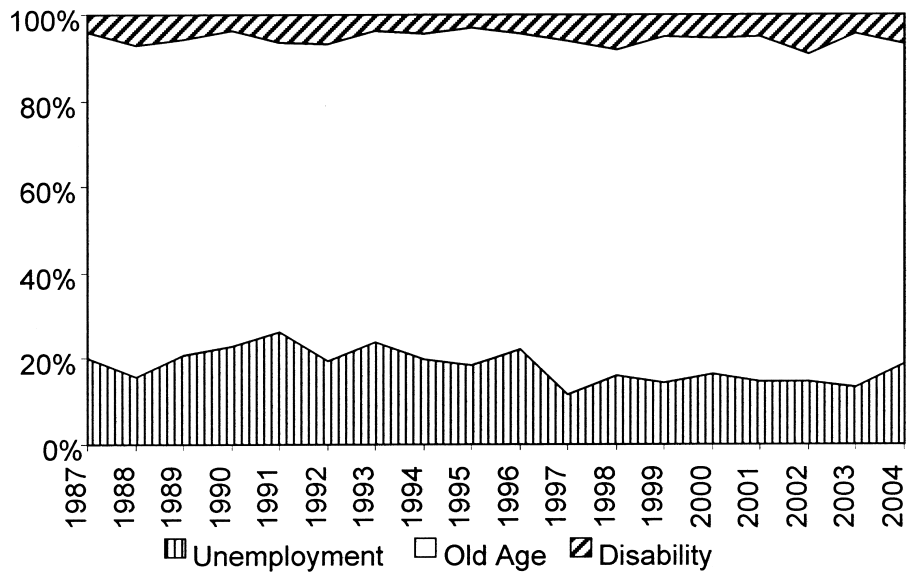

Fig. 11.6 Outflows from employment into unemployment, disability, and old age (men age fifty-five to sixty-four)

Source: Authors' own elaboration using data from the Spanish Labor Force Survey.

of interest. This is shown in figure 11.6. Unfortunately, the retrospective information does not distinguish between the different jobless statuses, which would have allowed us to identify the individuals that transit from unemployment or disability into retirement.

The share of individuals that leave employment and transit into unemployment is higher among the relatively younger individuals than among the older groups (50 percent of men age fifty-five to sixty that leave employment and transit to one of the statuses of interest go to unemployment compared 
to 20 percent among men age sixty to sixty-four). Disability insurance is the route less used to leave the labor market among older workers.

\subsubsection{Option Value Calculations}

In this section we describe the incentive measures used, as well as the necessary assumptions.

\section{SS Incentives Measures}

For a (representative) worker of age $a$, following Gruber and Wise (1999), we define social security wealth (SSW) in case of retirement at age $h \geq a$ as the expected present value of future pension benefits

$$
\mathrm{SSW}_{h}=\sum_{s=h+1}^{S} \rho_{s} B_{s}(h) .
$$

Here $S$ is the age of certain death, $\rho_{s}=\beta^{s-a} \pi_{s}$, with $\beta$ denoting the pure time discount factor and $\pi_{s}$ the conditional survival probability at age $s$ for an individual alive at age $a$, and $B_{s}(h)$ the pension expected at age $s \geq h+1$ in case of retirement at age $s$. Given SSW, we define the option value (OV) as follows:

$$
\mathrm{OV}_{a}=\max _{h}\left\{V_{h}-V_{a}\right\}, h=a+1, \ldots, R
$$

where

$$
V_{h}=\sum_{s=a+1}^{h} \rho_{s} W_{s}^{\gamma}+\sum_{s=h+1}^{S} \rho_{s}\left[k B_{s}(h)\right]^{\gamma}
$$

and $\rho_{s}$ are the survival probabilities, $S$ is age of (certain) death, and $W$ stands for earnings. We have imposed that $\beta=.97, \gamma=0.75$ and $k=1.5$. The conditional survival probabilities are obtained from INE (2010). Note that future benefits include spouse and survival benefits.

\section{Assumptions Made in Incentives Calculus}

We have computed social security incentive measures (SSW and OV) for the sample of individuals in SHARE 2004-2011. In order to compute the above incentives, the basic ingredients are wages (contribution histories) and family characteristics. Since SHARE does not provide accurate wage histories, we match individuals in SHARE to average wage histories in the Muestra Continua de Vidas Laborales 2011. ${ }^{17}$

From every year-of-birth, education, and gender cohort in the ECVL 2011 sample we construct the median wage distribution in the period 1981-2011. For example, for the group of individuals born in 1940, we recover covered wages from age forty-one to seventy. In general, for individuals born in 

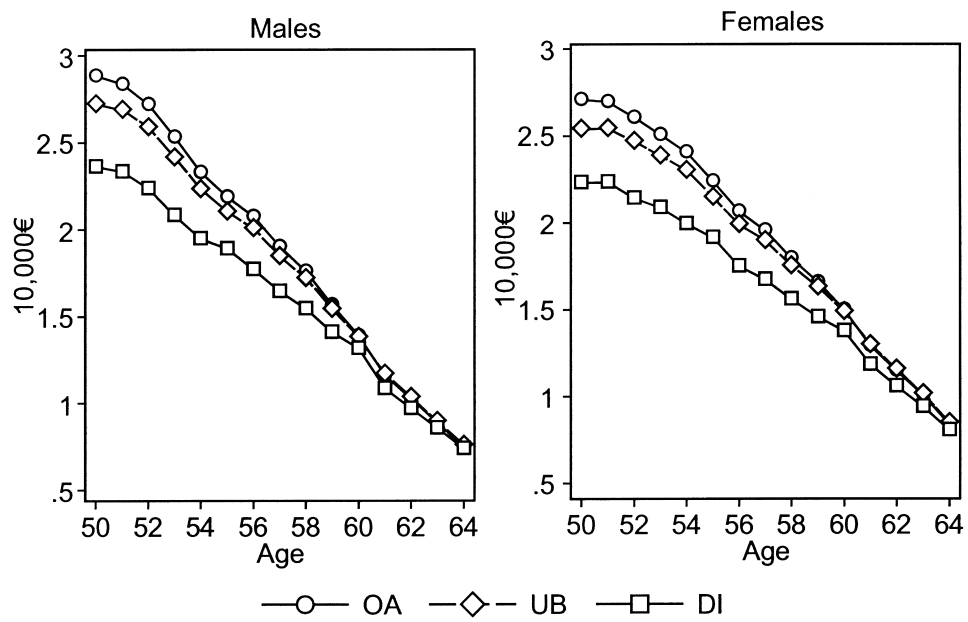

Fig. 11.7 Average OV for different pathways by gender

year $j$ we recover wages from the years 1981 to 2011 . Then we predict backward and forward in order to obtain a complete year of birth-gender-region wage profiles in the twenty to seventy age range. Wage profiles are projected assuming 1 percent real growth if there is no information (with 2 percent inflation after 2012). However, for ages fifty-nine and older we assume a 0 wage growth.

Regarding family characteristics, we use the information in SHARE for marital status. In addition, for both men and women, we assume that starting at age fifty-five and until a person reaches sixty-five, there are three pathways into retirement: unemployment benefits for individuals ages fifty-two and older (UB52+), disability insurance (DI), and early retirement (ER). At each particular age, the individual has an age-specific probability of going into retirement using any of these three programs. However, we have to take into account the following two restrictions: (a) a person has no access to the ER program before age sixty-one, and (b) after age sixty-one a person cannot claim UB52+ and can only claim ER or DI benefits.

Figure 11.7 plots the average OV for the three pathways considered (old age, unemployment, and disability) by gender. In all cases it is clear that the average $\mathrm{OV}$ is positive and decreasing with age, getting close to 0 as individuals approach sixty-five, as the incentives provided by the Spanish system to keep working beyond sixty-five are very low (see Jiménez-Martín and Sánchez-Martín 2007). We see that both for men and women the ranking in average OV among retirement pathways remains constant, that is, at any age the average $\mathrm{OV}$ for disability benefits is lower than the average OV for unemployment benefits, while the larger value is for the average OV for old-age retirement benefits. 

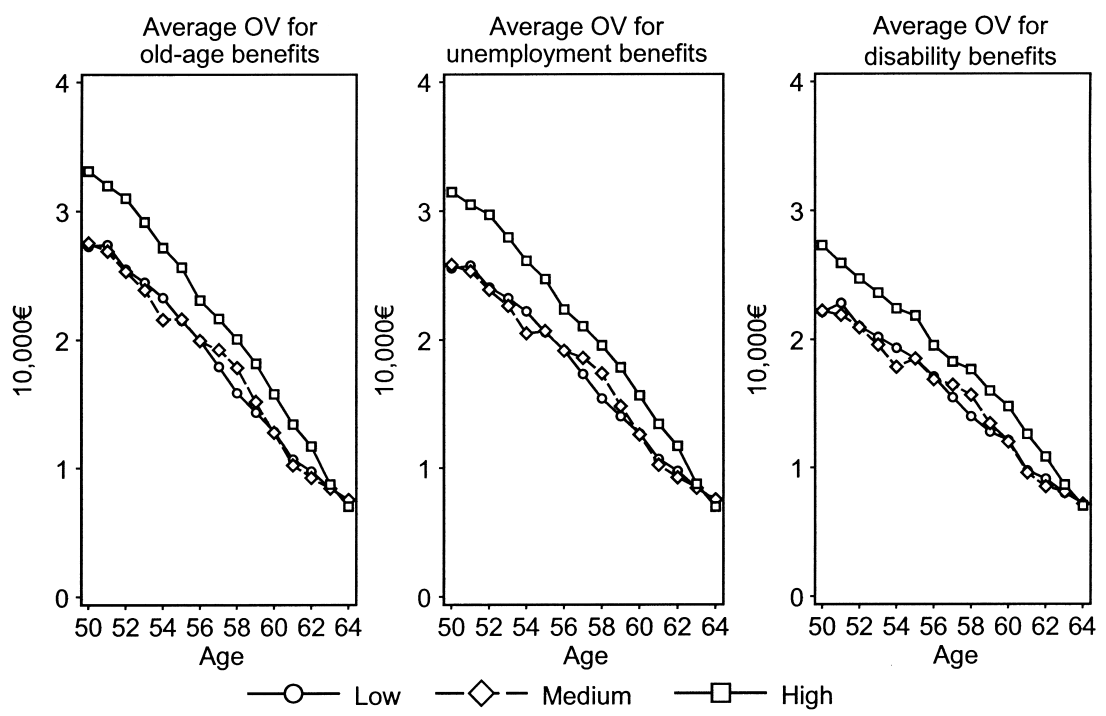

Fig. 11.8 Average OVs for different pathways by educational attainment (males)

We find that there is a clear gradient in the average OVs by educational attainment, as the OV for individuals with less than secondary education is lower than the OV for individuals with college for all the pathways into retirement (see figures 11.8 and 11.9). The difference disappears for individuals closer to the normal retirement age for males, and at ages sixty and older for females. In contrast, there are no differences in the average OV for individuals with low and medium educational attainment. In addition, the educational gradient is largest for unemployment benefits, implying that the gains from waiting are larger for educated individuals. This is not surprising since these individuals are less affected by incentives at the early retirement ages (for example, minimum pension incentives as pointed in Jiménez-Martín and Sánchez-Martín [2007]).

\subsubsection{Weighting the Pathways}

In the previous subsections we have seen that individuals in Spain use three different pathways to leave the labor market. Moreover, although the incentives to keep working in all cases decrease with age, the magnitude differs depending on the pathway used. Ideally, we would like to know how much weight an individual gives to each of the different possibilities, and use those to compute the financial incentives that he/she faces. However, the amount of information required for such a calculation may be very high and the assumptions needed very strong.

Instead, what we do is to impute to each observation the probability that each of the pathways (DI, unemployment, or old-age benefits) is a realistic 


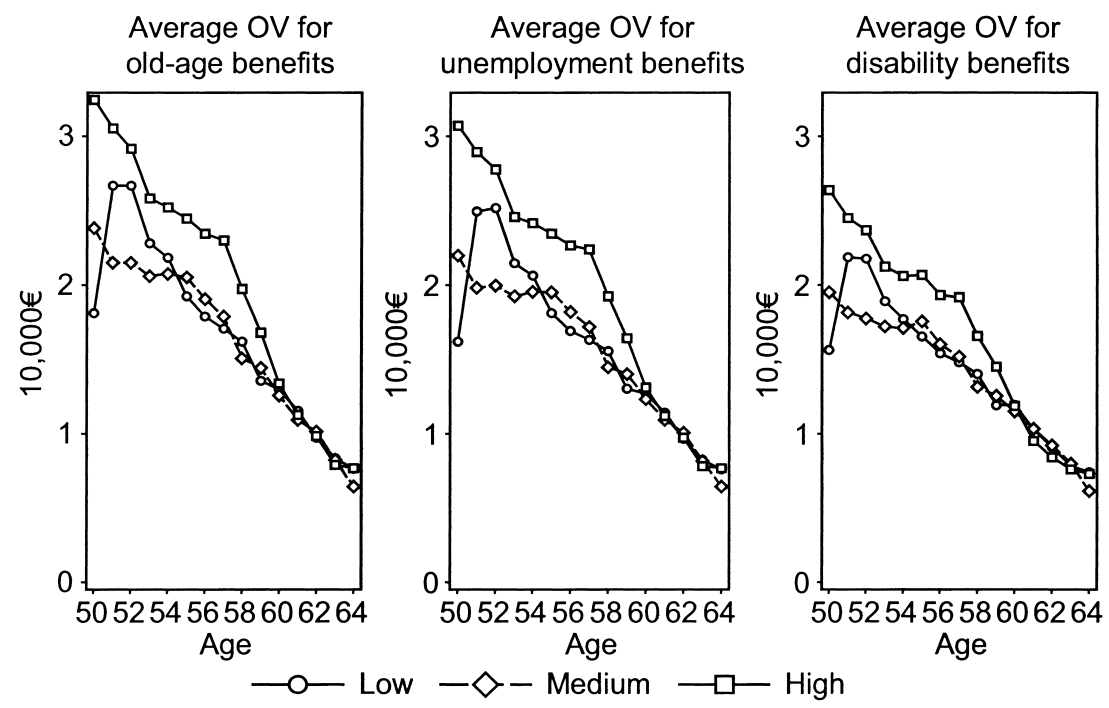

Fig. 11.9 Average OVs for different pathways by educational attainment (females)

option. These probabilities will then be used as weights in combining the paths into one option value number. We compute these probabilities using a set of exogenous characteristics of the individual. In particular, we use data from MCVL 2011 and compute for the population age fifty to sixty-four, the share that is receiving, in any given year, DI benefits, unemployment benefits, or old-age benefits. We calculate the probabilities separately by gender, year, and skill level.

These probabilities are reported in figure 11.10. We can see that the main difference between individuals with different educational attainment is related to the probability of being unemployed. Individuals with the lowest education (or skill level) are the ones with the highest probability of becoming unemployed in this age range. The administrative data also show that individuals in the highest skill level have the highest probability of being in the old-age benefits system, although the difference with respect to the other two groups is rather small. Last, the probability of being in DI is very similar for individuals in the medium- and low-skill level and slightly lower for the highest-skill group.

We then rescale these probabilities to one, and assign them to each of our individuals in our sample of analysis. We can think of this as an instrumental variable (IV) estimate of the probability, or the weight the person might assign to each of the possibilities.

The inclusive OV measure is therefore similar to the OV for unemployment benefits. This is due to two reasons. First, a large share of the population age fifty to sixty-four in Spain uses unemployment insurance as a 


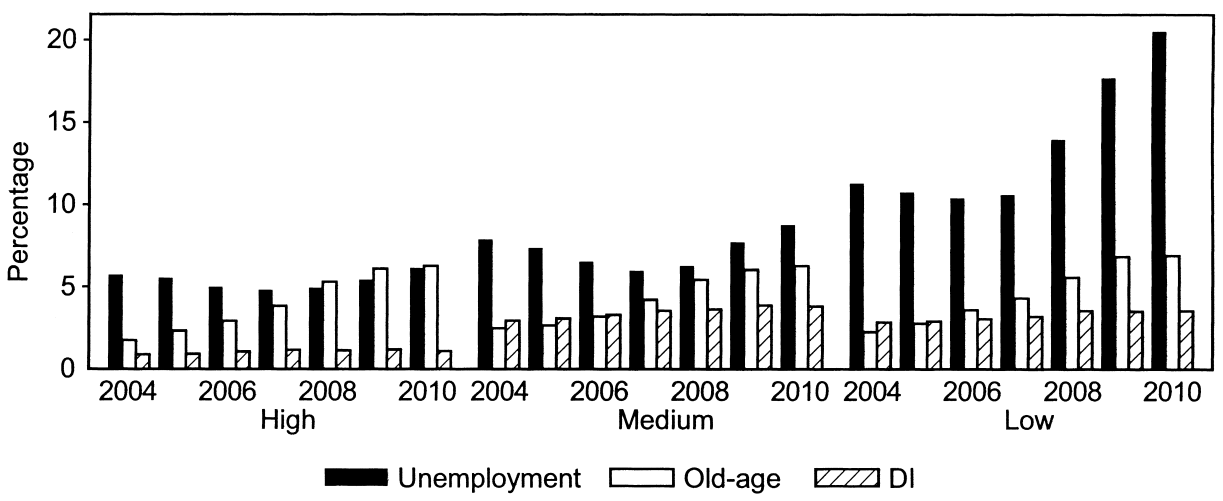

Fig. 11.10 Pathway probabilities by year and skill level for men ages fifty to sixty-four

Source: Authors' own elaboration using data from the Muestra Continua de Vidas Laborales (Spanish Social Security administrative data; see the appendix for details).

retirement scheme and, therefore, this is the scheme that may provide the largest incentives. Second, the OV for unemployment benefits lies in between old-age retirement benefits and disability benefits.

\subsubsection{Health Index and Health Quintiles}

We construct a single health index using a large set of variables available in the Survey of Health, Ageing and Retirement in Europe (SHARE) similar to Poterba, Venti, and Wise (2010). We use principal component analysis with all the observations and waves available. Notice that we exclude wave 3 as it does not contain health information.

Table 11.3 shows the factor loadings of the set of variables included in our synthetic health indicator. We see that the factor loading of all the variables have the correct sign. The variables with higher factors are those that capture whether the individual has difficulties with the (instrumental or basic) activities of daily living and self-assessed health. On the other hand, illnesses diagnosed by a doctor and health care use have a much lower factor loading.

We transform the health index so higher values are associated with better health. Then, we estimate for each individual in the SHARE sample his/her percentile in the health distribution. Figure 11.11 plots the mean percentile of the health index by age and gender. It shows that, as expected, there is a decreasing age trend in the average percentile of health index. In addition, at any age the average percentile among females is lower than the average percentile among males.

There are important differences in the characteristics of individuals in the different health quintiles. Table 11.4 shows descriptive statistics by health quintile for all individuals age fifty to sixty-four in our constructed database (see results section and appendix for data description). The group of indi- 


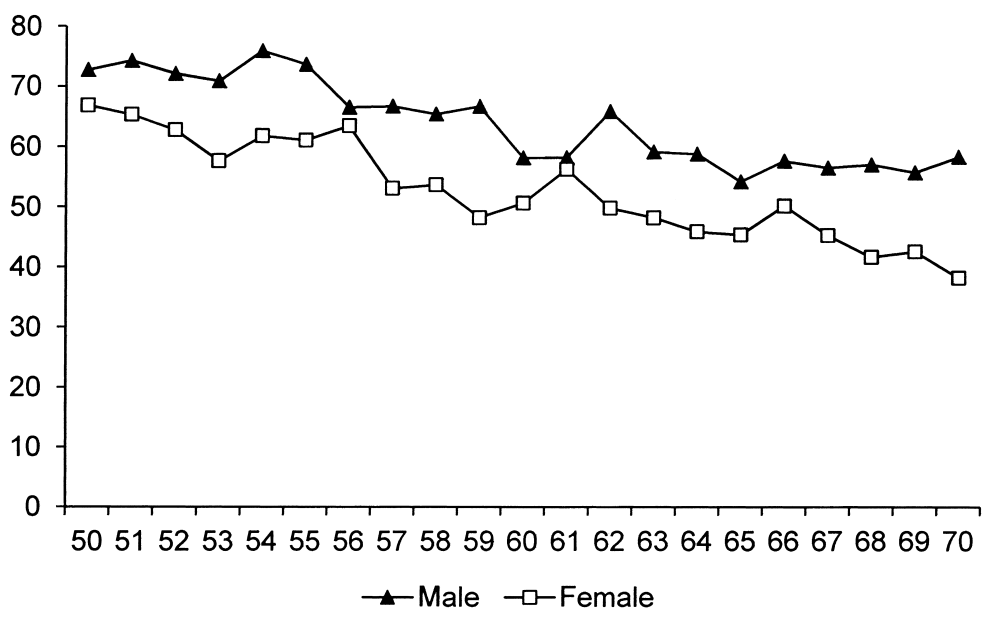

Fig. 11.11 Mean percentile of health index by age and gender

Source: We have used the entire Spanish SHARE sample from waves 1, 2, and 4 to calculate the health index and percentiles.

Table 11.4 Descriptives by health quintiles

\begin{tabular}{lccccc}
\hline & \multicolumn{5}{c}{ Health quintile } \\
\cline { 2 - 6 } & 1st (worst health) & 2nd & 3rd & 4th & 5th (best health) \\
\hline Male & 0.281 & 0.369 & 0.425 & 0.512 & 0.570 \\
Age & 58.6 & 58.2 & 57.3 & 56.8 & 56.4 \\
Less high school & 0.666 & 0.557 & 0.427 & 0.372 & 0.361 \\
High school & 0.291 & 0.377 & 0.464 & 0.458 & 0.472 \\
College & 0.042 & 0.066 & 0.109 & 0.170 & 0.167 \\
Employed & 0.189 & 0.337 & 0.450 & 0.586 & 0.639 \\
Unemployed & 0.049 & 0.069 & 0.064 & 0.079 & 0.069 \\
Retired & 0.401 & 0.376 & 0.374 & 0.253 & 0.155 \\
Disabled & 0.187 & 0.059 & 0.046 & 0.011 & 0.012 \\
OV inclusive & 17,444 & 17,025 & 17,911 & 18,442 & 18,372 \\
\hline
\end{tabular}

Note: The sample used to estimate shares of individuals in unemployment, retirement, or disability is smaller as it was not always possible to identify the exit route for those individuals who stopped working between SHARE waves.

viduals in worst health is characterized by having the largest share of older females with at most a primary education. In addition, the share of employed individuals is lower than in the other quintiles, while the share of disabled is much larger. It is worth noticing that while almost 20 percent of the individuals in the lowest health quintile claim to be receiving disability benefits, less than 6 percent of those in the second health quintile are on DI. There are not large differences in the average value of the inclusive OV, and they can be due to age differences. 


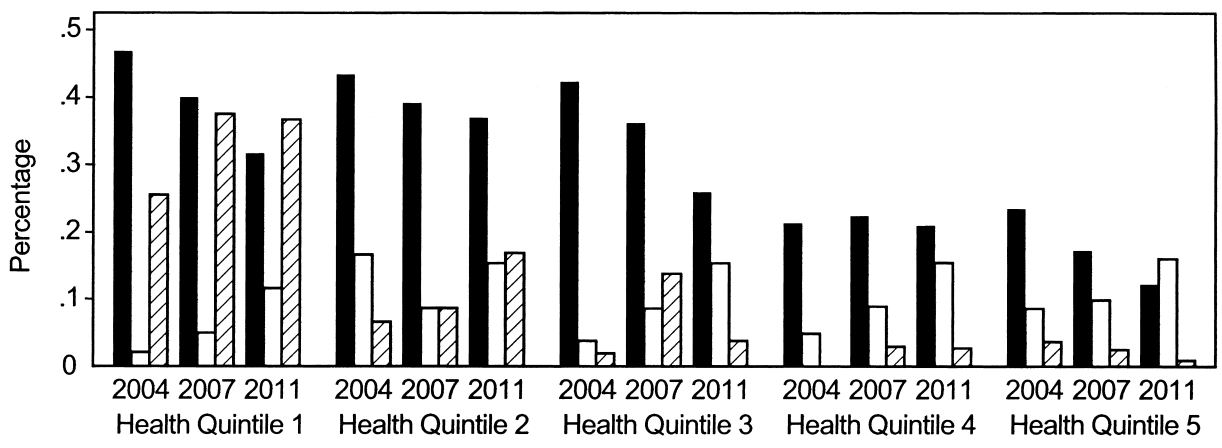

Retired $\square$ Unemployed $\square \not Z$ Disabled

Fig. 11.12 Percentage of individuals in each social security program by health quintile (men age fifty-five to sixty-four)

Source: Authors' own elaboration using data from SHARE.

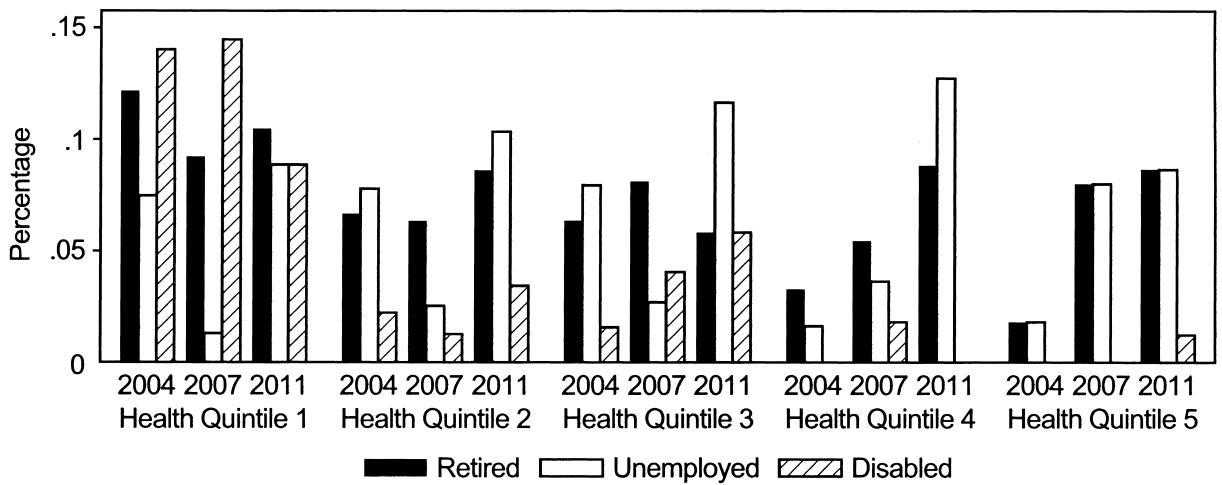

Fig. 11.13 Percentage of individuals in each social security program by health quintile (women age fifty-five to sixty-four)

Source: Authors' own elaboration using data from SHARE.

Figures 11.12 and 11.13 present the percentage of individuals in each social security program by health quintile for men and women ages fifty-five to sixty-four, respectively. As the results in table 11.4 showed, individuals in the worst health quintile are more likely to be disabled. However, figures 11.12 and 11.13 also show that the percentage of individuals in disability has increased for the other health quintiles in 2011, presumably as a result of the economics crisis. This is particularly important for women and for the second and third health quintiles.

Following with this evidence, figure 11.14 plots the percentage of individuals age fifty to sixty-four in DI for each health quintile and education level. Again, we observe that participation in DI is highly concentrated among 


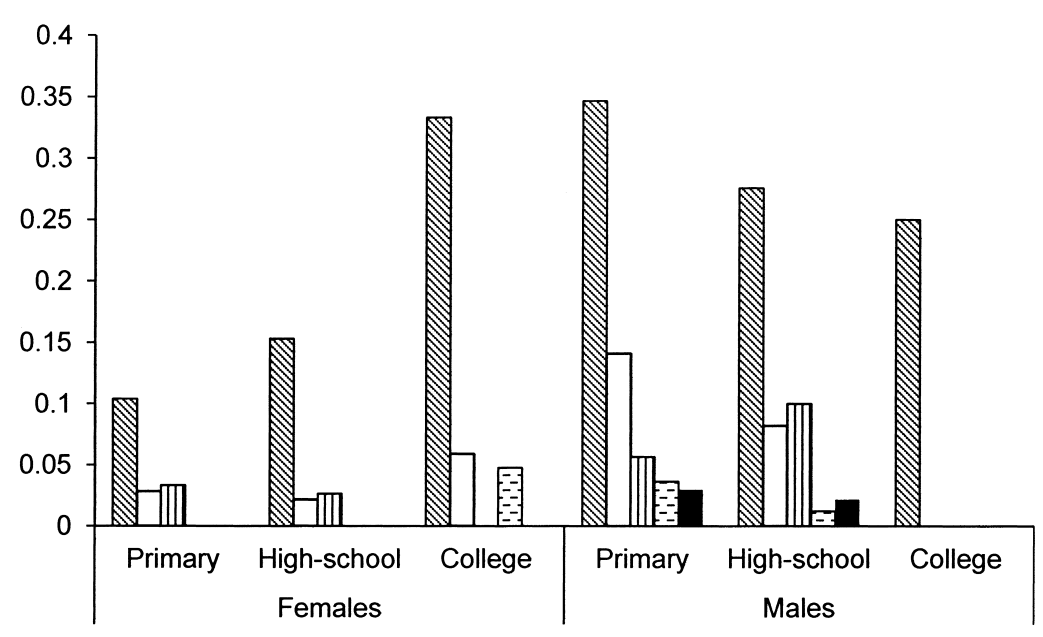

\&Quintile 1 (worst) पQuintile 2 QQuintile 3 घQuintile 4 Quintile 5 (best)

Fig. 11.14 The DI participation rate for men and women at ages fifty to sixty-four by health quintile and education

Source: Authors' own elaboration using data from SHARE.

those who report having very bad health. In fact, the percentage of individuals in DI for health quintiles other than the worst one is very low with the exception of men with a lower educational level.

Last, figure 11.15 shows that, although employment rates are generally higher for men than for women, both genders exhibit a similar pattern of employment by health quintile with those in the best health having the highest employment rates and those in the worst health having the lowest employment rates. The only exception to this pattern is for men age sixty to sixty-four, for which the highest employment rate is reported for those in the fourth health quintile.

Overall, we see that our health index measure captures reasonably well the well-known established facts with respect to the association of health and employment rates, DI participation, as well as education. In addition, it suggests that DI benefits in Spain are concentrated among those in the worst health, providing some evidence that the program is well targeted.

\subsection{Results}

We use the Spanish subsample from the Survey of Health, Ageing and Retirement in Europe (SHARE) to test the effect of financial incentives and health on transitions into retirement. We select the population age fifty to sixty-four (considering retirement at sixty-five) that respond to at least two waves and use an extensive definition of retirement that also includes 


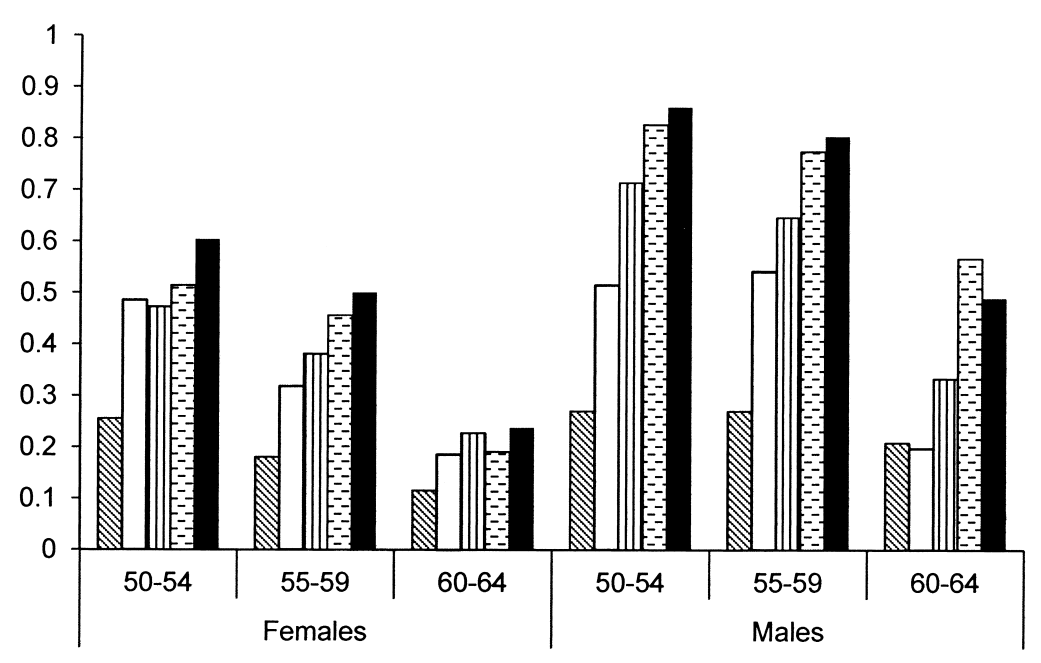

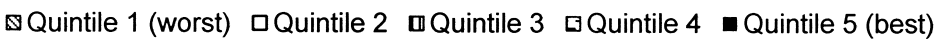

Fig. 11.15 Employment rates for men and women at ages fifty to sixty-four by health quintile

Source: Authors' own elaboration using data from SHARE.

unemployment and disability, as we have shown that these are also routes into retirement for the Spanish case. We combine retrospective employment information available in waves 2 and 4 , with job episodes from SHARELIFE to construct a yearly panel from 2004 to 2010 . We detail the procedure used in the appendix. We select individuals who are working at $t$ and look at the probability that they are nonemployed in $t+1$. Our final sample contains 1,682 observations for 451 individuals.

We use a series of probit models to estimate the probability of retirement as a function of the OV-inclusive measure, the health status measured in health quintiles, and a set of sociodemographic characteristics. Table 11.5 summarizes the results. The effect of the OV-inclusive measure always has the expected negative sign, that is, the larger the value of continuing working, the lower the probability of retirement, although it is not significant. The magnitude and significance of the effect are not affected by the specification of age (linear or age dummies), the health specification (health quintiles or continuous health index), or the inclusion of further covariates.

The sign of the effect of the rest of the variables is as expected. In particular, individuals in better health are less likely to stop working, although the difference is not statistically significant between individuals in the second lowest health quintile and individuals in the lowest quintile (omitted group). We see that individuals in all the other groups are at least 5.8 percentage points less likely to retire compared to individuals in poorest health.

As it has been found in many studies for the Spanish case (see, for ex- 


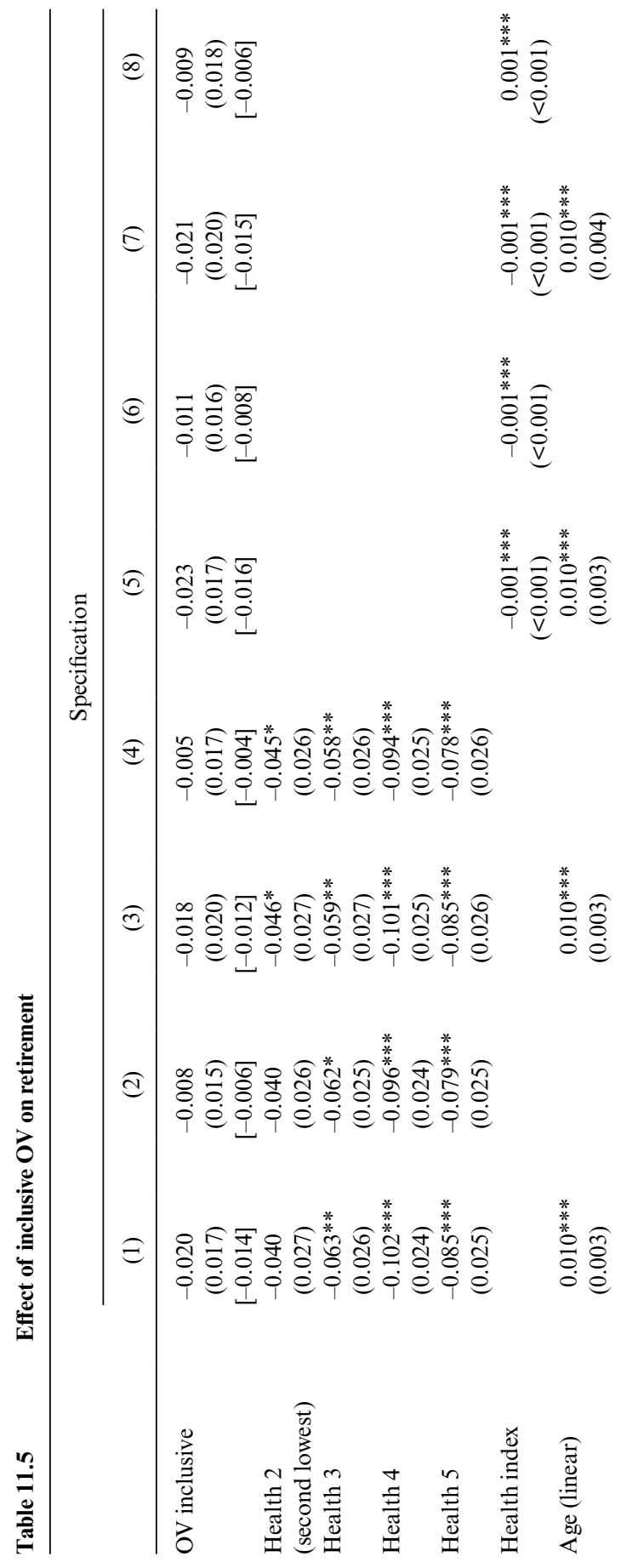




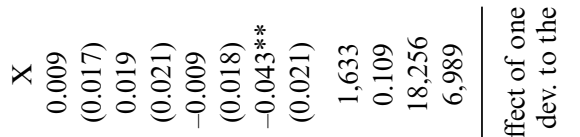

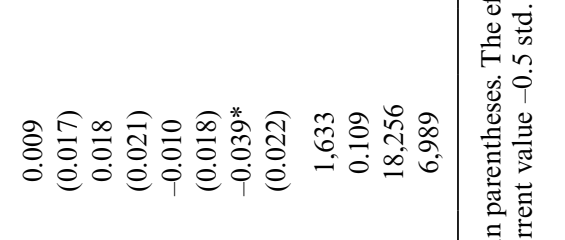

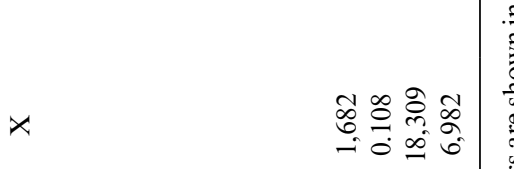

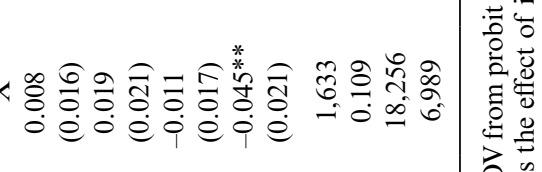

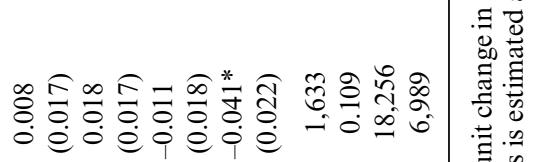

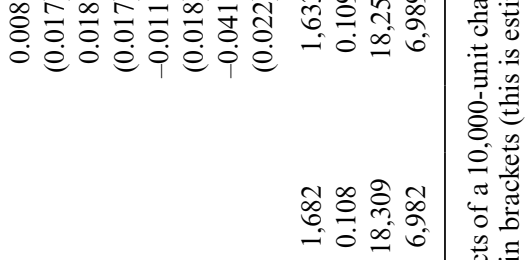

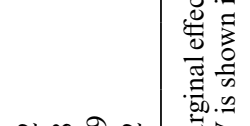

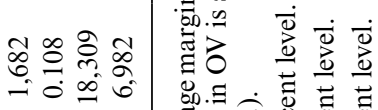

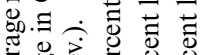

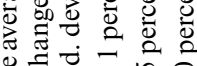

$$
\begin{aligned}
& \text { 응 }
\end{aligned}
$$

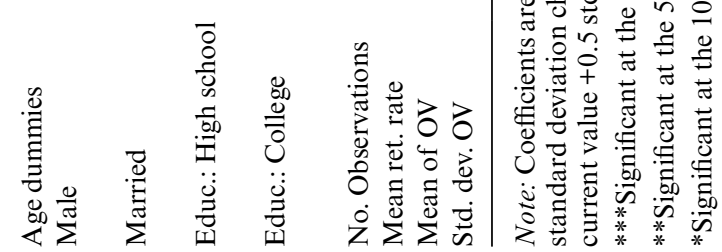


A. Retirement hazard, Men

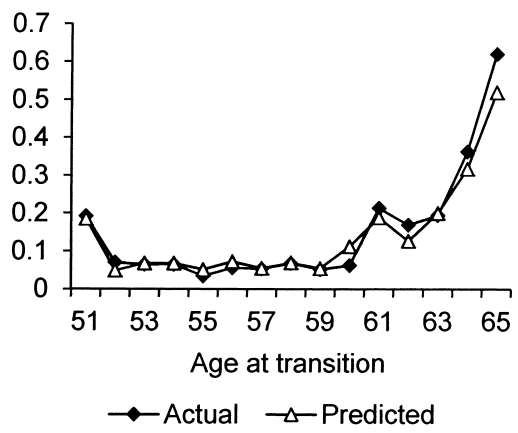

C. Survival, Men

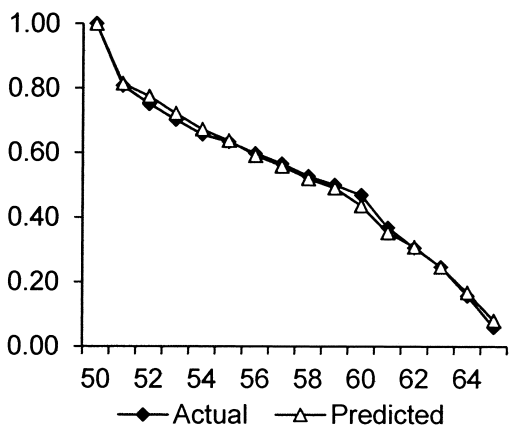

B. Retirement hazard, Women
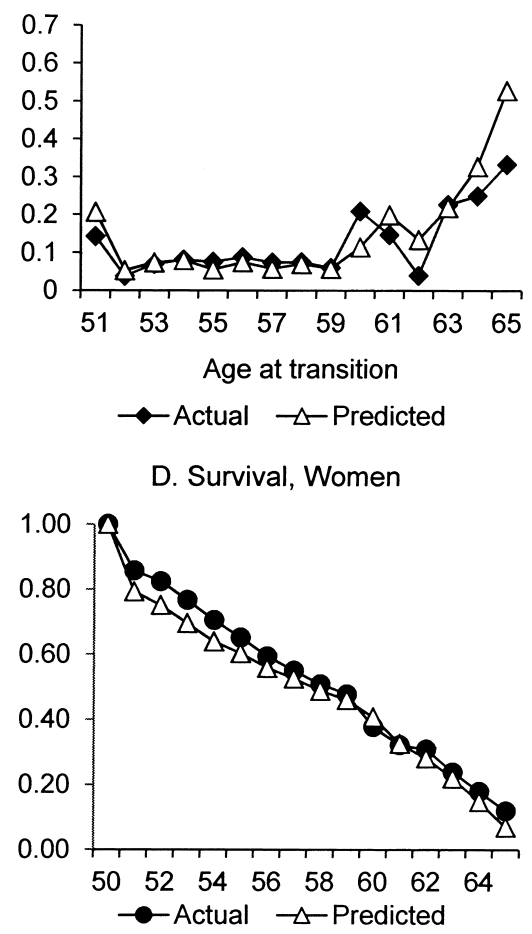

Fig. 11.16 Actual versus predicted retirement hazard and survival by gender

ample, Jiménez-Martín and Sánchez-Martín 2007), the hazard of retirement is lower for individuals with at least a high school education compared to individuals with lower educational attainment. Results show that individuals with a high school degree are around 1 percentage point less likely to retire compared to individuals with a primary education at most, although these differences are not statistically significant. Last, individuals with college are around 4 percentage points less likely to retire compared to individuals with less than high school education.

Figure 11.16 shows actual versus predicted retirement rates by age for both men (panel A) and women (panel B) and predicted survival rates for men (panel C) and women (panel D). The figures are based on estimates from specification (4) in table 11.5. The predicted hazard and survival curve rate are closer to the actual ones for males compared to females. This is not surprising because we have fewer observations for females, so the observed behavior is much more noisy. For example, only thirty-five women in our sample workers are at least sixty-three years of age.

Table 11.6 shows similar results where OV-inclusive has been substituted by the percent gain in utility units from delaying retirement, that is, the utility 


\begin{tabular}{lcccc}
\hline & \multicolumn{4}{c}{ Specification } \\
\cline { 2 - 5 } & $(1)$ & $(2)$ & $(3)$ & $(4)$ \\
\hline Percent gain in OV & -0.044 & -0.042 & -0.033 & -0.036 \\
& $(0.046)$ & $(0.038)$ & $(0.054)$ & $(0.046)$ \\
Linear age & $\mathrm{X}$ & & $\mathrm{X}$ & \\
Age dummies & $\mathrm{X}$ & $\mathrm{X}$ & $\mathrm{X}$ & $\mathrm{X}$ \\
Health quintiles & & & $\mathrm{X}$ & $\mathrm{X}$ \\
Other Xs & 1,682 & 1,682 & 1,633 & 1,633 \\
No. of observations & 0.108 & 0.108 & 0.109 & 0.109 \\
Mean ret. rate & 0.812 & 0.812 & 0.804 & 0.804 \\
Mean of \% gain in OV & 0.342 & 0.342 & 0.338 & 0.338 \\
Std. dev. of \% gain in OV & & & \\
\hline
\end{tabular}

Notes: Models are the same as models $1-4$ in table 11.5. Coefficients are average marginal effects. Standard errors are shown in parentheses.

gain from waiting to retire at the optimal date scaled by the utility available by retiring today. We have computed this measure as follows:

$$
\% \text { Gain }=P_{\mathrm{DI}} * \% \mathrm{Gain}_{\mathrm{DI}}+P_{\mathrm{UI}} * \% \mathrm{Gain}_{\mathrm{UI}}+P_{\mathrm{OA}} * \% \mathrm{Gain}_{\mathrm{OA}} .
$$

The results are similar to those shown before. They are robust to the age specification and the inclusion of further controls.

As discussed above, there are large differences in the characteristics of individuals in the different health quintiles. In addition, we have seen that those in the best health are less likely to retire. Figure 11.17 shows the predicted hazard rate for each health quintile by gender. Hazard rates are constructed using estimates from specification (3) shown in table 11.5 that includes age linearly. The differences in predicted hazard rates between health quintiles are larger for males compared to females. Males in the two lowest health quintiles have a lower probability of retirement at any age compared to males in the highest two health quintiles. Males in the second-lowest quintile have the same hazard of retirement as those in worst health until age fifty-nine, but the hazard of retirement in the lowest quintile becomes higher compared to all the other health quintiles after age sixty.

Differences in health status may not only explain differences in the hazard of retirement but, in addition, individuals may react differently to changes in the financial incentives depending on their health status. It is not possible to get a priori any theoretical predictions as the health level may be an important determinant of several of the parameters that enter in the OV, as future string of income, the marginal disutility of labor, change in preferences, or the adjustment of the survival probabilities (Erdogan-Ciftci, Van Doorslaer, and Lopez Nicolas 2011).

In order to test this hypothesis, we further estimate the previous models 


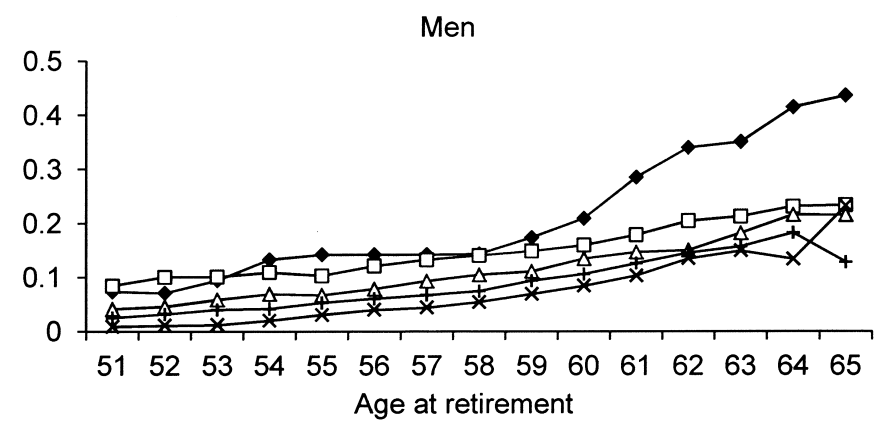

$\rightarrow$ Quintile1 $\neg-$ Quintile2 $\triangle-$ Quintile3 $\rightarrow$ Quintile4 $\rightarrow$ Quintile5

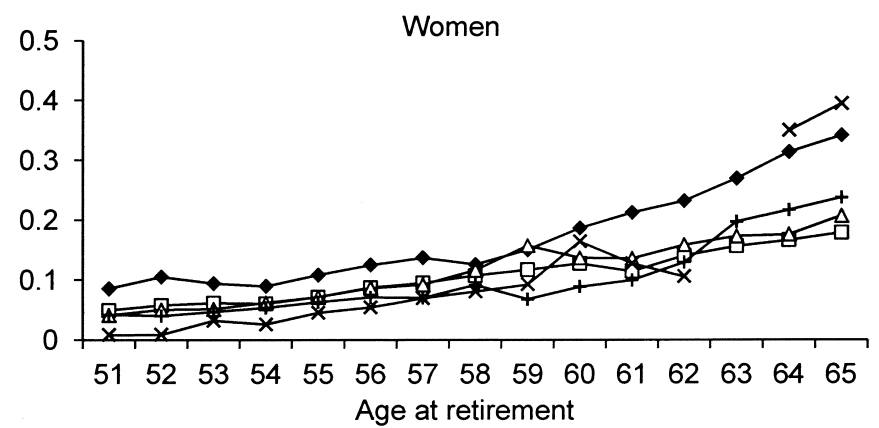

$\rightarrow$ Quintile1 $\neg-$ Quintile2 $\triangle-$ Quintile3 $\rightarrow$ Quintile4 $\rightarrow$ Quintile5

Fig. 11.17 Predicted hazard rate by health quintile and gender

separately for each of the five quintiles. We show only models that include a linear age specification, as the small number of observations in each of the subsamples prevents us from including age dummies. However, we would expect results not to be sensitive to this choice based on previous results (as shown in table 11.5). Table 11.7 shows results when the inclusive OV is included and table 11.8 when the percent gain is included.

In general, we see that the magnitude of the effect is robust to the inclusion of further controls. The differences by health quintile reveal an interesting pattern. We find that only individuals in the lowest health quintile respond to financial incentives. These results suggest that an increase of 10,000 units decreases the probability of retirement by 12 percentage points among individuals in the lowest health quintile, while an increase of one standard deviation increase in the $\mathrm{OV}$-inclusive measure decreases the probability of retirement by about 8.5 percentage points.

We further explore the relationship between the inclusive OV and health, estimating the same model as the one shown in table 11.7 but including interactions between the inclusive OV and the health index. The marginal effects are shown in table 11.9. The conclusion one would draw from these 
Effect of inclusive $\mathrm{OV}$ on retirement by health quintile

\begin{tabular}{|c|c|c|c|c|c|c|}
\hline & \multirow{2}{*}{$\begin{array}{l}\text { No. of } \\
\text { obs. }\end{array}$} & \multirow{2}{*}{$\begin{array}{l}\text { Mean } \\
\text { ret. rate }\end{array}$} & \multirow{2}{*}{$\begin{array}{l}\text { Mean } \\
\text { of OV }\end{array}$} & \multirow{2}{*}{$\begin{array}{l}\text { Std. dev. } \\
\text { of OV }\end{array}$} & \multicolumn{2}{|c|}{ Specification } \\
\hline & & & & & (1) & (3) \\
\hline $\begin{array}{l}\text { OV: Lowest quintile } \\
\text { (worst health) }\end{array}$ & 337 & 0.184 & 16,604 & 6,878 & $\begin{array}{c}-0.122^{* * *} \\
(0.044) \\
{[-0.084]}\end{array}$ & $\begin{array}{c}-0.129^{* * *} \\
(0.048) \\
{[-0.090]}\end{array}$ \\
\hline OV: 2nd quintile & 339 & 0.121 & 18,512 & 6,987 & $\begin{array}{c}0.049 \\
(0.036) \\
{[0.034]}\end{array}$ & $\begin{array}{c}0.039 \\
(0.042) \\
{[0.028]}\end{array}$ \\
\hline OV: 3rd quintile & 334 & 0.102 & 18,358 & 6,749 & $\begin{array}{c}-0.044 \\
(0.044) \\
{[-0.030]}\end{array}$ & $\begin{array}{r}-0.024 \\
(0.052) \\
{[-0.016]}\end{array}$ \\
\hline OV: 4 th quintile & 342 & 0.056 & 19,916 & 7,126 & $\begin{array}{c}0.002 \\
(0.031) \\
{[0.002]}\end{array}$ & $\begin{array}{c}0.023 \\
(0.033) \\
{[0.016]}\end{array}$ \\
\hline $\begin{array}{l}\text { OV: Highest quintile } \\
\text { (best health) }\end{array}$ & 330 & 0.076 & 18,128 & 6,794 & $\begin{array}{c}0.005 \\
(0.035) \\
{[0.003]}\end{array}$ & $\begin{array}{r}-0.002 \\
(0.038) \\
{[-0.001]}\end{array}$ \\
\hline $\begin{array}{l}\text { Linear age } \\
\text { Other Xs }\end{array}$ & & & & & $\mathrm{X}$ & $\begin{array}{l}X \\
X\end{array}$ \\
\hline
\end{tabular}

Notes: Models are the same as models 1 and 3 in table 11.5, but are estimated separately by health quintile; each coefficient in the table is from a different regression. Coefficients are average marginal effects of a 10,000-unit change in OV from probit models. Standard errors are shown in parentheses. The effect of one standard deviation change in OV is shown in brackets (this is estimated effect as the effect of increasing inclusive $\mathrm{OV}$ from the current value -0.5 std. dev. to the current value +0.5 std. dev.).

*** Significant at the 1 percent level.

**Significant at the 5 percent level.

*Significant at the 10 percent level.

results is that there are no differences in the effects of the OV-inclusive for individuals with different values of the health index. However, the small magnitude and significance of the interaction shown in table 11.9 is due to the fact that only individuals in the lowest health quintile are affected by changes in the OV-inclusive, as shown in tables 11.7 and 11.8.

We have argued that there are some differences in the hazard rates by educational attainment. Figure 11.18 shows the predicted hazard rate for each of the educational groups by gender. Hazard rates are constructed using estimates from specification (3) shown in table 11.5 that includes age linearly. The results show that less-educated males are more likely to retire after the age of sixty (by the time the retirement program becomes available), while those with secondary education have the highest hazard rate at lower ages (by the time the disability program and the unemployment program are the only options). An educational gradient appears among females older than fifty-five and the differences in hazard rates widen with age. 


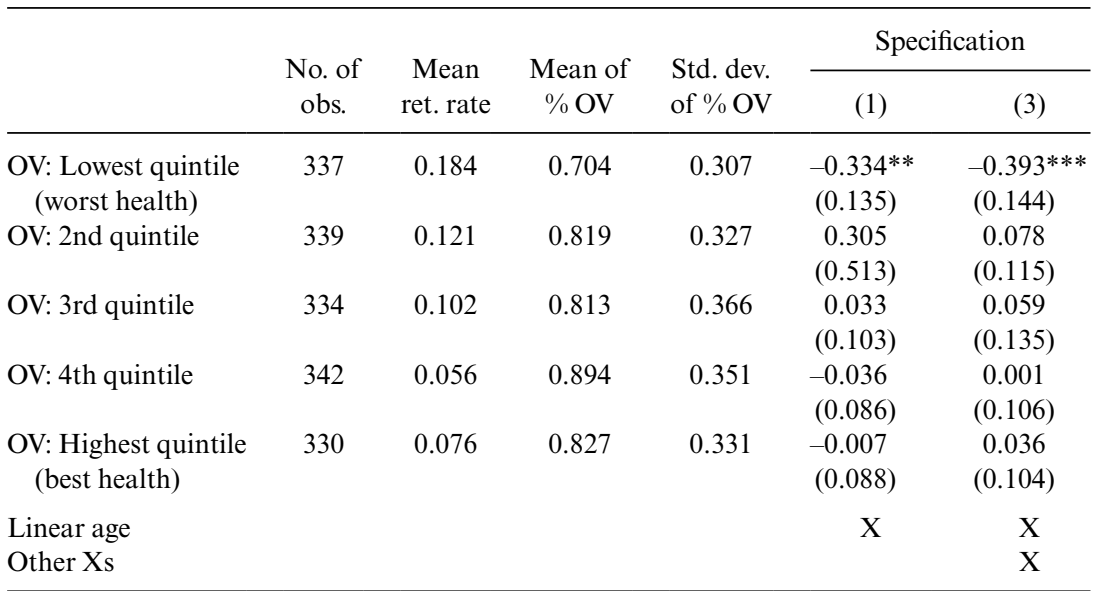

Notes: Models are the same as models 1 and 3 in table 11.6, but are estimated separately by health quintile; each coefficient in the table is from a different regression. Coefficients are marginal effects. Standard errors are shown in parentheses.

***Significant at the 1 percent level.

**Significant at the 5 percent level.

*Significant at the 10 percent level.

Table 11.9

Effect of inclusive $\mathrm{OV}$ on retirement with health index interaction

\begin{tabular}{lcccc}
\hline & \multicolumn{4}{c}{ Specification } \\
\cline { 2 - 5 } & $(1)$ & $(2)$ & $(3)$ & $(4)$ \\
\hline OV inclusive & -0.055 & -0.024 & -0.059 & -0.026 \\
& $(0.035)$ & $(0.032)$ & $(0.036)$ & $(0.033)$ \\
Health index & $-0.002^{* * *}$ & $-0.002^{* *}$ & $-0.002^{* * *}$ & $-0.002^{* *}$ \\
& $(0.001)$ & $(0.001)$ & $(0.001)$ & $(0.001)$ \\
OV*health index & $<0.001$ & $<0.001$ & $<0.001$ & $<0.001$ \\
& $(<0.001)$ & $(<0.001)$ & $(<0.001)$ & $(<0.001)$ \\
Linear age & $\mathrm{X}$ & & $\mathrm{X}$ & \\
Age dummies & & $\mathrm{X}$ & $\mathrm{X}$ & $\mathrm{X}$ \\
Other Xs & 1,682 & 1,682 & 1,633 & 1,633 \\
Number of observations & & & & \\
\hline
\end{tabular}

Note: Coefficients are average marginal effects of a 10,000-unit change in OV from probit models. Standard errors are shown in parentheses. The effect of one standard deviation change in $\mathrm{OV}$ is shown in brackets (this is estimated as the effect of increasing inclusive OV from the current value $-0.5 \mathrm{std}$. dev. to the current value $+0.5 \mathrm{std}$. dev.).

$* * *$ Significant at the 1 percent level.

**Significant at the 5 percent level.

*Significant at the 10 percent level. 

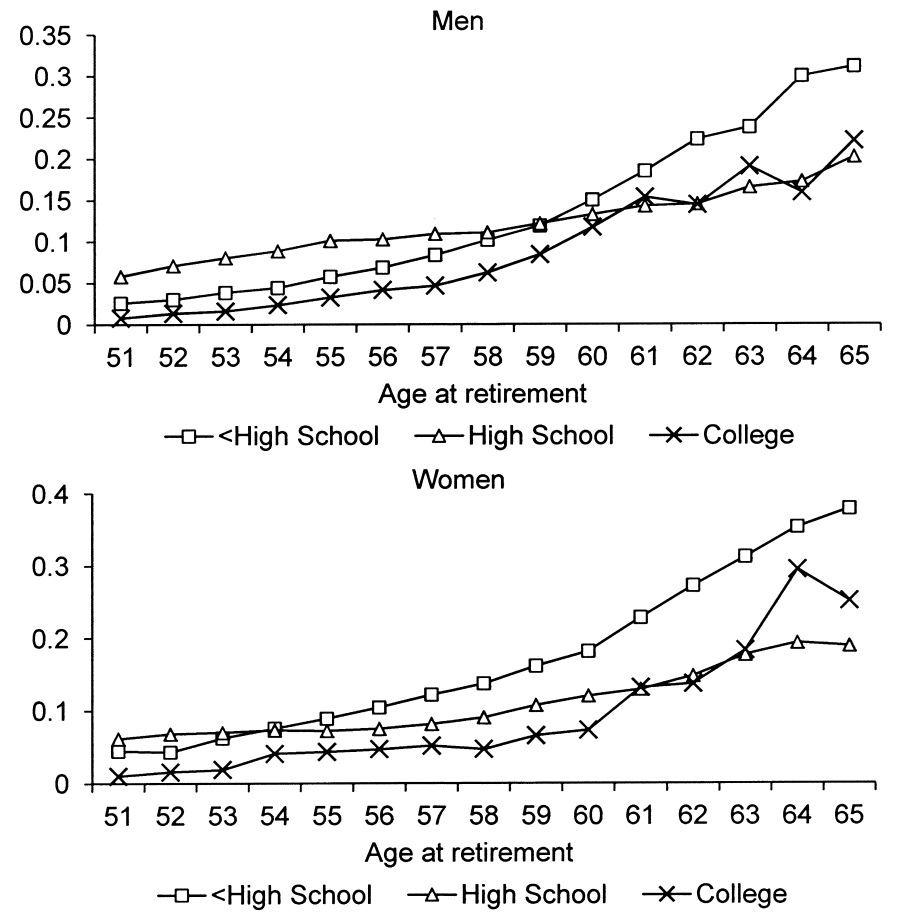

Fig. 11.18 Predicted hazard rate by educational attainment and gender

Table 11.10 Effect of inclusive OV on retirement by education group

\begin{tabular}{|c|c|c|c|c|c|c|}
\hline & \multirow{2}{*}{$\begin{array}{c}\text { No. of } \\
\text { obs. }\end{array}$} & \multirow{2}{*}{$\begin{array}{l}\text { Mean } \\
\text { ret. rate }\end{array}$} & \multirow{2}{*}{$\begin{array}{l}\text { Mean } \\
\text { of OV }\end{array}$} & \multirow{2}{*}{$\begin{array}{l}\text { Std. dev. } \\
\text { of OV }\end{array}$} & \multicolumn{2}{|c|}{ Specification } \\
\hline & & & & & (1) & (3) \\
\hline OV: Less than high school & 600 & 0.137 & 16,837 & 7,030 & $\begin{array}{c}0.016 \\
(0.035) \\
{[0.011]}\end{array}$ & $\begin{array}{c}0.008 \\
(0.034) \\
{[0.066}\end{array}$ \\
\hline OV: High school & 747 & 0.104 & 17,719 & 6,028 & $\begin{array}{r}-0.017 \\
(0.029) \\
{[-0.010]}\end{array}$ & $\begin{array}{c}-0.024 \\
(0.030) \\
{[-0.014]}\end{array}$ \\
\hline OV: College & 286 & 0.063 & 22,639 & 7,511 & $\begin{array}{r}-0.043 \\
(0.033) \\
{[-0.033]}\end{array}$ & $\begin{array}{r}-0.050 \\
(0.035) \\
{[-0.038]}\end{array}$ \\
\hline $\begin{array}{l}\text { Linear age } \\
\text { Other Xs }\end{array}$ & & & & & $\mathrm{X}$ & $\begin{array}{l}X \\
X\end{array}$ \\
\hline
\end{tabular}

Note: Models are the same as models 1 and 3 in table 11.5, but are estimated separately by education group; each coefficient in the table is from different regression. Coefficients are average marginal effects of a 10,000-unit change in OV from probit models. Standard errors are shown in parentheses. The effect of one standard deviation change in OV is shown in brackets (this is estimated as the effect of increasing inclusive OV from the current value $-0.5 \mathrm{std}$. dev. to the current value $+0.5 \mathrm{std}$. dev.). 
Table 11.11

Effect of gain on retirement by educational attainment

\begin{tabular}{|c|c|c|c|c|c|c|}
\hline & \multirow{2}{*}{$\begin{array}{c}\text { No. of } \\
\text { obs. }\end{array}$} & \multirow{2}{*}{$\begin{array}{l}\text { Mean } \\
\text { ret. rate }\end{array}$} & \multirow{2}{*}{$\begin{array}{c}\text { Mean } \\
\text { of } \% \\
\text { OV }\end{array}$} & \multirow{2}{*}{$\begin{array}{c}\text { Std. dev. } \\
\text { of } \% \\
\text { OV }\end{array}$} & \multicolumn{2}{|c|}{ Specification } \\
\hline & & & & & (1) & (3) \\
\hline OV: Less than high school & 600 & 0.137 & 16,837 & 7,030 & $\begin{array}{c}-0.041 \\
(0.101)\end{array}$ & $\begin{array}{c}-0.016 \\
(0.096)\end{array}$ \\
\hline OV: High school & 747 & 0.104 & 17,719 & 6,028 & $\begin{array}{c}0.023 \\
(0.079)\end{array}$ & $\begin{array}{c}-0.019 \\
(0.087)\end{array}$ \\
\hline OV: College & 286 & 0.063 & 22,639 & 7,511 & $\begin{array}{c}-0.096 \\
(0.082)\end{array}$ & $\begin{array}{c}-0.090 \\
(0.095)\end{array}$ \\
\hline $\begin{array}{l}\text { Linear age } \\
\text { Other Xs }\end{array}$ & & & & & $\mathrm{X}$ & $\begin{array}{l}X \\
X\end{array}$ \\
\hline
\end{tabular}

Notes: Models are the same as models 1 and 3 in table 11.6, but are estimated separately by health quintile; each coefficient in the table is from a different regression. Coefficients are marginal effects. Standard errors are shown in parentheses.

We estimate both the effect of inclusive OV and the percent gain on retirement by each of the three educational groups. The results are shown in tables 11.10 and 11.11 . The results show that although the magnitude of the effect is larger among more educated individuals, it is never statistically significant.

\subsection{Conclusions}

This chapter investigates the role of financial incentives and health in the retirement behavior of Spanish workers. We shed light on the different pathways that individuals choose to leave the labor market, and incorporate the incentives from the different systems (disability insurance, old-age retirement scheme, and unemployment insurance) in one single measure.

We use data from the Spanish sample of the Survey of Health and Retirement to model transitions out of employment. In general, although we find the expected sign in incentive variables, they are not significant. This is likely due to insufficient variability of simulated incentive indicators caused by the impossibility to construct individual wage profiles. Still, we are able to offer support for some interesting conclusions. For example, we show that the effects of the incentives from the different social security schemes on employment behavior seem to be concentrated among individuals in the worst health, while all the other groups seem not to be affected. In addition, health status plays an important role in explaining transitions out of employment as individuals in the worst health quintile are twice as likely to retire compared to individuals in the best health quintile.

In order to better understand the incentives provided by the different 
schemes, we provide a set of simulations in which we assume that individuals can only access one of the social security programs. The simulations show that there are small differences in the number of years a person would work if faced by different types of programs. This should not cause any surprise because there are small differences in the level of incentives provided by the various programs available to individuals in Spain.

\section{Appendix}

\section{The Database Muestra Continua de Vidas Laborales (Continuous Sample of Working Lives)}

The Continuous Sample of Working Lives (Muestra Continua de Vidas Laborales [MCVL]) is a microeconomic data set based on administrative records provided by the Spanish Social Security Administration. Each wave contains a random sample of 4 percent of all the individuals who had contributed to the social security system (either by working or being on an unemployment scheme) or had received a contributory pension during at least one day in the year the sample is selected. For these workers, the database contains the complete labor market and contributory benefits history since they entered the labor market for the first time.

There is information available on the entire employment, unemployment, and pension history of the workers, including the exact duration of employment, unemployment, and disability or retirement pension spells, and for each spell, several variables that describe the characteristics of the job or the unemployment/pension benefits. There is also some information on personal characteristics such as age, gender, nationality, and level of education.

\section{Construction of Yearly Panel Using SHARE}

We first use waves 1, 2, and 4 of SHARE. We identify all transitions between waves using retrospective information about all employment and unemployment spells, as well as transitions into retirement available in waves 2 and 4 . We complement these transitions with information from SHARELIFE. In order to impute the date of interview (relevant for transitions and age at wave) we assume that the individual is interviewed in the same month as in the last wave in which he/she is observed.

We estimate health percentiles using information from waves 1,2 , and 4 and compute individual average annual growth rates to impute changes in health between waves. Education, date of birth, and gender do not vary over time and, therefore, information from existing waves can be used. 


\section{References}

Boldrin, M., P. García- Gómez, and S. Jiménez- Martín. 2010. "Social Security Incentives, Exit from the Workforce and Entry of the Young." In Social Security Programs and Retirement around the World: The Relationship to Youth Employment, edited by Jonathan Gruber and David A Wise. Chicago: University of Chicago Press.

Boldrin, M., and S. Jiménez- Martín. 2007. "Evaluating Spanish Pension Expenditure under Alternative Reform Scenarios." In Social Security Programs and Retirement around the World: Fiscal Implications for Reform, edited by Jonathan Gruber and David A Wise. Chicago: University of Chicago Press.

Boldrin, M., S. Jiménez-Martín, and F. Peracchi. 1999. "Social Security and Retirement in Spain." In Social Security and Retirement around the World, edited by J. Gruber and D. Wise. Chicago: University of Chicago Press.

Börsch-Supan, A. 2000. "Incentive Effects of Social Security on Labor Force Participation: Evidence in Germany and across Europe." Journal of Public Economics 78 (1-2): 25-49.

Coile, C., and J. Gruber. 2007. "Future Social Security Entitlements and the Retirement Decision." Review of Economics and Statistics 89 (2): 234-46.

Diamond, P. A. 2007. "Top-Heavy Load: Trouble Ahead for Social Security Systems." CESifo Forum 8 (3): 28-36.

Dorn, D., and A. Souza-Poza. 2010. "'Voluntary' and 'Involuntary' Early Retirement: An International Analysis." Applied Economics 42 (4): 427-38.

Erdogan-Ciftci, E., E. Van Doorslaer, and A. Lopez Nicolas. 2011. "Does Declining Health Affect the Responsiveness of Retirement Decisions to Financial Incentives?" Netspar Discussion Paper no. 01/2011-005, Network for Studies on Pensions, Aging and Retirement.

Eurostat. 2013. "Towards a 'Baby Recession' in Europe?” Statistics in Focus 13. Brussels.

Fenge, R., and P. Pestieau. 2005. "Social Security and Early Retirement." Cambridge, MA: MIT Press.

García-Gómez, P., S. Jiménez-Martín, and J. Vall Castelló. 2012. "Health, Disability and Pathways into Retirement in Spain." In Social Security and Retirement around the World: Historical Trends in Mortality and Health, Employment, Disability Insurance Participation and Reforms, edited by D. Wise, 127-74. Chicago: University of Chicago Press.

García-Pérez, J. I., S. Jiménez-Martín, and A. Sánchez-Martín. 2013. "Retirement Incentives, Individual Heterogeneity and Labour Transitions of Employed and Unemployed Workers." Labour Economics 20:106-20.

Gruber, J., and D. A. Wise, eds. 1999. Social Security and Retirement around the World. Chicago: University of Chicago Press.

- 2004. Social Security Programs and Retirement around the World: MicroEstimation. Chicago: University of Chicago Press.

Hagan, R., A. M. Jones, and N. Rice. 2009. "Health and Retirement in Europe." International Journal of Environmental Research and Public Health 6:2676-95.

Instituto Nacional de Estadística (INE). 2010. Tablas de Mortalidad de la Población Española. Madrid.

Jiménez-Martín, S. 2006. "Evaluating the Labor Supply Effects of Alternative Reforms of the Spanish Pension System." Moneda y Crédito 222:271-312.

Jiménez-Martín, S., and A. R. Sánchez-Martín. 2007. "An Evaluation of the Life Cycle Effects of Minimum Pensions on Retirement Behavior." Journal of Applied Econometrics 22 (5): 923-50. 
Jimenez-Martin, S., and J. Vall Castelló. 2013. "Business Cycle and Spillover Effects on Pre-Retirement Behavior in Spain." Journal of European Labor Studies 2:8.

Kerkhofs, M., M. Lindeboom, and J. Theeuwes. 1999. "Retirement, Financial Incentives and Health." Labour Economics 6 (2): 203-27.

Lutz, W., W. Sanderson, and S. Scherbov. 2008. "The Coming Acceleration of Global Population Ageing." Nature 451 (7179): 716-19.

Organisation for Economic Co-operation and Development (OECD). 2001. "Economic Survey-Spain.” Paris, OECD.

Poterba, J. M., S. F. Venti, and D. A. Wise. 2010. "Family Status Transitions, Latent Health, and the Post-Retirement Evolution of Assets." NBER Working Paper no. 15789, Cambridge, MA.

Samwick, Andrew. 1998. "New Evidence on Pensions, Social Security, and the Timing of Retirement." Journal of Public Economics 70:207-36.

Vall Castelló, J. 2012. "Promoting Employment of Disabled Women in Spain: Evaluating a Policy." Labour Economics 19 (1): 82-91.

Wise, D., ed. 2012. Social Security Programs and Retirement around the World: Historical Trends in Mortality and Health, Employment, and Disability Insurance Participation and Reforms. Chicago: University of Chicago Press. 